\title{
Supra-Normal Age-Linked Retrograde Amnesia: Lessons From an Older Amnesic (H.M.)
}

\author{
Donald G. MacKay* and Christopher Hadley
}

\begin{abstract}
MacKay and James (2001) demonstrated greater-thannormal retrograde amnesia (RA) for lexical-semantic information in amnesic H.M., a deficit that worsened with aging or represented supranormal age-linked RA (SARA). The present experiments extend these earlier observations to new types of information. Experiment 1 participants (H.M. and carefully matched memory-normal controls) named pictures on the Boston Naming Test and H.M. correctly named reliably fewer pictures with low frequency names, he produced unusual naming errors, and he benefited reliably less than the controls from phonological cues to the target word. Experiment 2 participants recalled irregularly-spelled aspects of familiar words in a two-choice recognition memory task and H.M. chose the correct spelling reliably less often than the controls. Experiment 3 participants read low frequency words aloud at age 73 and H.M. produced reliably more reading errors than the controls. Results of all three experiments indicate supranormal RA (SRA) for information once familiar to H.M. and comparisons with earlier studies using similar or identical stimuli indicated that H.M.'s SRA has worsened with aging from 1980 to 1999. In short, H.M. exhibits SARA for phonological and orthographic information, consistent with the MacKay and James results and with interactions between aging and amnesia predicted under binding theory. $\odot 2008$ Wiley-Liss, Inc.
\end{abstract}

KEY WORDS: $\quad$ retrograde; amnesia; H.M.; aging

\section{INTRODUCTION}

Retrograde amnesia (RA) normally refers to long-term deficits in the ability of amnesics to retrieve information acquired years and sometimes decades before the brain trauma that caused their amnesia (see e.g., Kapur, 1993). However, normal cognitive aging also causes RA. By way of illustration, normal older adults exhibit deficits relative to young adults in remembering names they once knew for familiar objects pictured in the Boston Naming Test (BNT), in remembering the phonology of low-frequency (LF) words they once retrieved without difficulty, in retrieving the meaning and phonology of visually presented LF words that they once read aloud without difficulty, and in remembering irregularly spelled aspects of LF words they once spelled without error (for a recent review, see Burke and Shafto, 2008). Moreover, these normal agelinked deficits in phonological, orthographic and lexical retrieval become progressively worse as a function of aging (see e.g., Barresi et al., 2000;

Psychology Department, University of California, Los Angeles

Grant sponsor: The Samuel A. MacKay Memorial Research Fund and NIH; Grant number: R01 AG 09755.

*Correspondence to: Donald G. MacKay, Psychology Department, University of California, Los Angeles, CA 90095-1563.

E-mail: mackay@ucla.edu

Accepted for publication 1 October 2008

DOI 10.1002/hipo.20531

Published online 29 December 2008 in Wiley InterScience (www. interscience.wiley.com).
Burke et al., 2004; Burke et al., 1991; James and MacKay, 2007; MacKay and Abrams, 1998; MacKay et al., 1999; Rastle and Burke, 1996; Van Gorp et al., 1986). Strictly speaking, amnesics therefore exhibit supranormal RA (SRA), i.e., RA that exceeds the normal age-linked RA that occurs in same-age controls.

James and MacKay (2001) and MacKay and James (2002) demonstrated a new dimension to SRA in the famous amnesic H.M.: supranormal age-linked RA (SARA). SARA involves RA for familiar information that progresses with aging at a faster-than-normal rate. Such exaggerated or accelerated effects of aging have so far only been demonstrated in H.M. for limited types of information and for a restricted age range. The present study attempts to establish the existence of SARA in H.M. across a wider age range and for new types of information. We first review the empirical evidence for lexical-semantic SARA in H.M. We then examine the significance of SARA for theories of cognitive aging and amnesia.

SARA FOR LEXICAL-SEMANTIC INFORMATION: AN EMPIRICAL REVIEW

Three experiments in James and MacKay (2001) demonstrated SARA for lexical-semantic information (see MacKay and James, 2002, for other evidence of SARA in H.M.). Participants in one experiment were H.M. at age 73 , cerebellar patients, and memory-normal controls matched with H.M. for age, IQ, and education. Their task was to define words that were either high-frequency (HF), e.g., What does payment mean?, or LF, e.g., What does squander mean? When defining LF words, H.M. produced two unusual types of errors not produced by either the cerebellar patients or the normal controls: misderivation and malaprop errors. Misderivation errors were definitions based on incorrect morphological analyses of a stimulus word. For example, H.M. defined the LF word lentil as a blend of the words lent and till: "that's a combination word, in a way, from lent and till... (meaning) area and time of." Malaprop errors were definitions that matched a phonologicallysimilar word better than the target word. For example, H.M. defined the verb to squander as if it meant to plunder: "squander is uh. . . to take things as one's own, other persons' things" (for a complete list of H.M.'s misderivation and malaprop errors, see Table 1). 
TABLE 1.

H.M.'s Full Set of Misderivation (MD) and Malaprop (MP) Errors for LF Words and Pseudowords That he Mistakenly Claimed Were Words in James and MacKay (2001)

\begin{tabular}{lll}
\hline Stimulus & H.M.'s incorrect definitions & Correct (control) definitions
\end{tabular}

Lentil (LF word)

Efface (LF word)

Retrend (Pseudoword)

Unmelt (Pseudoword)

Labyrinth (LF word)

Squander (LF word)

Primp (LF word)

Jettison (LF word)

Chameleon (LF word)

Sulk (LF word)

Hence (HF word)

Pediodical (Pseudoword)

Reversement (Pseudoword)
H.M.: Lentil. That's a combination word, in a way, from lent and till. (L.J. ${ }^{a}$ : So what would that mean put together?) Well, area and time of. (MD)

H.M.: Well, that one I have an argument with myself, well, it- it could- I think of deface right away (laugh). (L.J.: Right. . .) And efface would be to, to make uh a picture of something. (MD)

H.M.: And retread, that could be the tire on a car, retread, or something that's redone. (L.J.: This one's actually different.) H.M.: Retrend. (L.J.: Yes.) H.M.: And, the way of doing something different, the way something is done different, two ways. (MD)

H.M.: Melt is, unmelt, rather. That is something to stay s- uh stiff or... not uh melted in any way. (MD)

H.M.: Labrinth. Actu- that's uh, labrinth, and that's uh the burying place of the periods(?) long ago. (L.J.: A burying place from long ago?) From long ago. (MP)

H.M.: And squander is uh... to take things as one's own, other persons' things. (MP)

H.M.: And then primp, and that could be uh meaning, something extraordinary that you enjoy. (L.J.: Some- I'm sorry I didn't hear you.) Something extraordinary that you enjoy. (MP)

H.M.: Jetson means uh, well thrown out of something... (L.J.: Good...) (mumble) or something. (L.J.: This one actually has the " $\mathrm{i}$ " in the middle. That's right for the definition of jetsam but this one with the " $\mathrm{i}$ " means it's the word jettison.) Jettison. (L.J.: Do you know what jettison is?) To be thrown out of, some- well, say the cockpit of a plane, or something like that, jettison. And uh you were thrown out of it, naturally, first. (MP)

H.M.: Chameleon, you think of uh, a jewel. (L.J.: A jewel?) A red jewel. (L.J.: A red jewel?) Yeah. From France. (MP)

H.M.: And sulk is to uh... well, you- um. . . abide by something, sulk over it, you uh th- think of it as different. (MP)

H.M.: Hence is uh, may be. (MP)

H.M.: Pediodical. About the same thing as periodical." (MP)

H.M.: Amusement. (L.J.: Read it again.) H.M.: Rearmusement is uh... (L.J. : Read it one more time.) H.M.: Reversement. That is to, take the- what it is, can be, should be. (MP)
Lentil is a bean, a what- a legume.

Efface means to wear away.

Nonword

Nonword

Labyrinth is like a maze.

Squander is to waste.

Primp is to sit before the mirror and primp yourself up, make yourself look good, or you do the same thing for a dog or a cat.

Jettison is to throw away.

Chameleon is a small type of reptile that changes color very easily.

Sulk is to be sad, depressed.

Hence means forthcoming or to be.

Nonword

Nonword

\footnotetext{
${ }^{a}$ L.J. was the experimenter.
} 
Detailed analyses of H.M.'s word use in 1970 ruled out educational deficiency as the basis for H.M.'s misderivation and malaprop errors: H.M. used LF words correctly in 1970 that he defined incorrectly in 1997, an unlikely outcome given failure to learn during childhood. These observations suggested that previously familiar LF words had become meaningless to H.M., and consistent with this "defunct meaning" hypothesis, H.M. produced misderivation and malaprop errors when attempting to define truly meaningless pseudowords that he mistakenly claimed were words (see Table 1 for examples).

Also consistent with the defunct meaning hypothesis, H.M. correctly defined only $29 \%$ of the LF words in James and MacKay (2001), a reliable deficit relative to the memory-normal controls (and the cerebellar patients, ruling out H.M.'s cerebellar damage as the basis for this deficit). However, H.M. correctly defined $2 \%$ more HF words than the controls (92\%), indicating that H.M.'s deficit was confined to LF words.

James and MacKay (2001) next conducted a longitudinal study of H.M.'s memory for lexical-semantic information in lexical decision tasks administered at age 57 and age 73. Relative to same-age memory-normal controls, H.M. exhibited a small but reliable lexical decision deficit for LF words at age 57 (indicating SRA) and a significantly larger deficit for LF words at age 73 , when his lexical decision performance for LF words approximated chance responding $(50 \%)$. This greater-than-normal age-linked decline in H.M.'s ability to retrieve once familiar LF information in the 15 years between age 57 and 73 indicates SARA, i.e., greater-than-normal RA that has worsened with aging relative to same-age controls. However, for $\mathrm{HF}$ words, H.M. exhibited no deficits in lexical decision performance at either age, a finding that cannot be explained in terms of either "task difficulty" or across-the-board cognitive decline.

\section{THEORETICAL SIGNIFICANCE OF SARA}

According to James and MacKay (2001), H.M.'s SARA for lexical-semantic information indicated degradation with aging in two layers of bottom-up links in the cortex: the layer connecting orthography and phonology to the lexical nodes for words, and the layer connecting lexical nodes to the propositions that define word-meanings. Figure 1 illustrates these two levels of bottom-up links for the LF adjective squeamish. At the highest level, the lexical node for squeamish links bottom-up to proposition-level nodes in the semantic system that represent its meaning, e.g., easily offended. At the lower level, nodes representing the syllables and other hierarchically organized phonological components of squeamish link bottom-up to its lexical node. Broken lines in Figure denote the degradation in these bottom-up links that in theory caused H.M.'s SRA for semantic information.

Understanding the effects of aging on SRA or lesion-induced memory deficits in H.M. requires an understanding of the basic cause of normal forgetting and age-linked forgetting, discussed next.

\section{Aging and Normal Forgetting}

A basic cause of normal forgetting in the James-MacKay theory is a theoretical process known as transmission deficits (see James and MacKay, 2001; Burke, 2006; Burke and Shafto, 2008; and MacKay and Burke, 1990). Transmission deficits reduce the transmission of priming across cortical connections and can prevent node activation, a process essential for retrieving a word and its associated orthography, phonology, and propositions. The reason is that priming is necessary to prepare a connected node for activation: Unless sufficient priming is transmitted to a node, it cannot become activated and the information it represents cannot be retrieved.

Three factors increase the magnitude of transmission deficits: nonrecent use of information, infrequent use of information over the lifespan, and aging (see e.g., MacKay and Burke, 1990; Burke et al., 2004; James and Burke, 2000; James and MacKay, 2007; and Rastle and Burke, 1996, for experimental evidence indicating that aging, nonrecent use, and lifetime use independently impact retrieval failures and transmission deficits). All three factors reduce the extent of neurotransmitter uptake the across the synapses between cortical neurons (see MacKay and Burke, 1990), although the mechanisms underlying these effects are unspecified in the theory. However, the theory does specify the differing extent of the connections impacted by aging vs. nonrecent and infrequent use. Transmission deficits because of nonrecent and infrequent use are connection-specific, affecting only those connections with infrequent or nonrecent use. By contrast, transmission deficits because of aging are connection-universal and node-universal in the theory, affecting all types of cortical connections (bottomup, lateral, and top-down) and all types of cortical nodes (e.g., phonological, orthographic, and lexical). Age-linked transmission deficits will therefore exacerbate or compound any transmission deficits that arise from infrequent or nonrecent use.

To illustrate this compounding process for specific connections in specific tasks, consider a hypothetical young and older adult who have used the LF word squeamish recently and frequently during their life spans. In a meaning definition task, the older adult will correctly define squeamish with lower probability than the young adult because age-linked transmission deficits will reduce the delivery of bottom-up priming from the lexical node for squeamish to its proposition nodes (see Fig. 1), thereby reducing the probability of activating the stored propositions for defining squeamish. Similarly, in a lexical decision task, the older adult will respond that squeamish is a word with lower probability than the young adult because age-linked transmission deficits will reduce the delivery of bottom-up priming from orthographic and phonological nodes to the lexical node representing squeamish (see Fig. 1), thereby reducing the probability of activating this lexical node and identifying squeamish as a meaningful word.

Because age-linked transmission deficits become progressively worse with aging, such activation or retrieval failures will become progressively more likely with aging. However, recent and frequent use or activation can reverse this trend up to a 


\section{SEMANTIC SYSTEM}

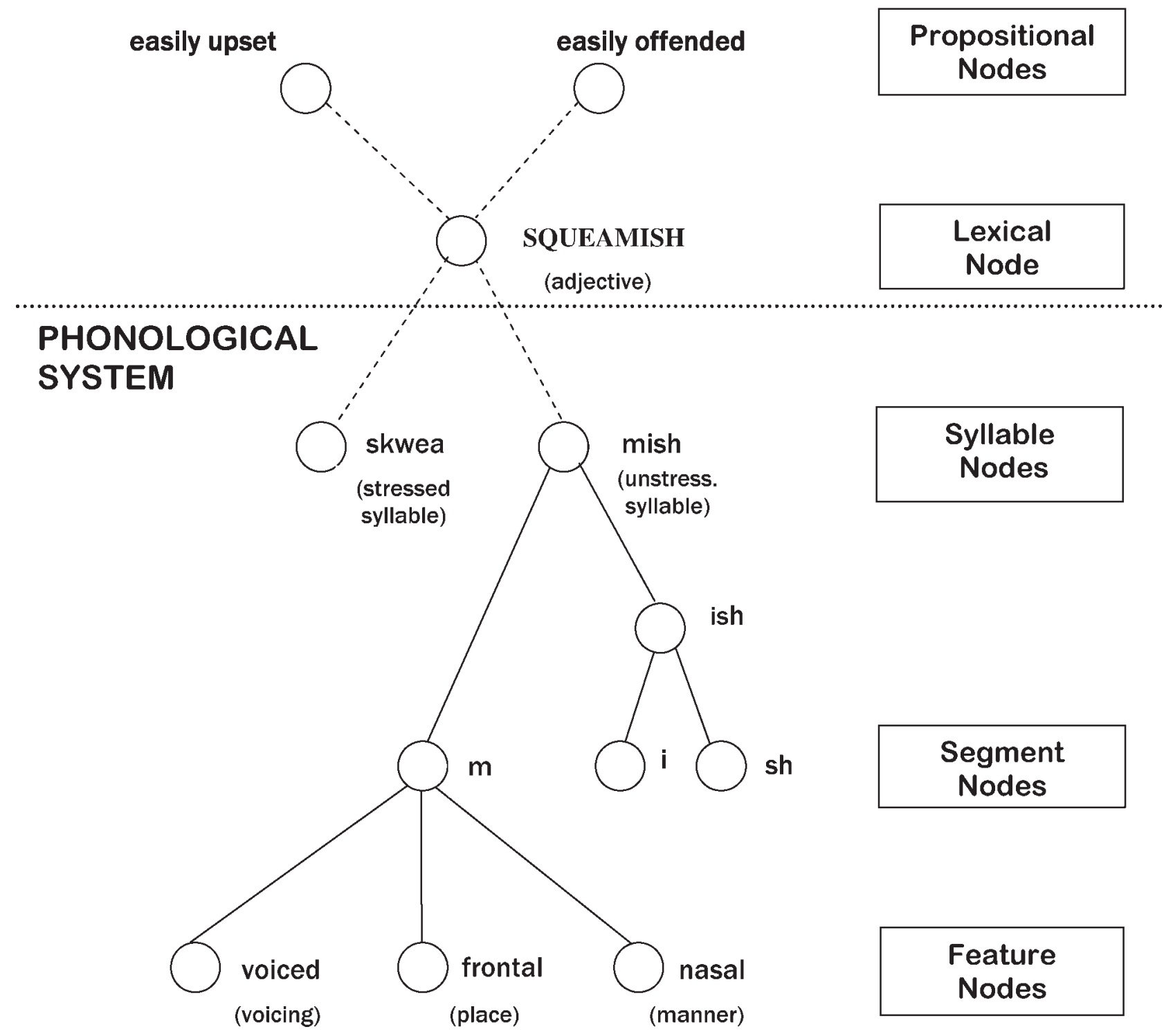

FIGURE 1. A subset of the top-down nodes representing the adjective squeamish in the semantic and phonological systems (with many nodes omitted for simplicity). Solid lines represent functional connections. Broken lines represent connections that have become nonfunctional because of age-linked transmission deficits.

point. For example, older adults unable to retrieve the consonant cluster /skw/ in squeamish can overcome this retrieval failure by reading other words that contain the /skw/ cluster, e.g., squint, squall, and squander (see James and Burke, 2000). (This report distinguishes phonological from orthographic units using the generally accepted convention of capitalizing orthographic units within square brackets, and placing phonological units between slashes, as in this example. To further illustrate this distinction, the suffix in farmer is represented /-êr/ in phonology and [-ER] in orthography, and the initial letters in SQUEAMISH are represented /skw/ phonologically and [SQU] orthographically. Our phonological transcriptions of spoken speech follow the current International Phonetic Alphabet [available at: www.arts.gla.ac.uk/IPA/fullchart.html]).

Nonetheless, there comes a point during normal aging when age-linked transmission deficits across specific connections become so extensive and severe that rarely- and not-recentlyused nodes become defunct or nonfunctional, i.e., none of their connections transmit sufficient priming to enable activation of the node. For example, if the node representing the consonant cluster $/ \mathrm{skw} /$ in squeamish has become defunct because of nonrecent use, infrequent use across the lifespan, and extreme old age, presenting words that contain the $/ \mathrm{skw} /$ cluster, e.g., squint, squall, and squander, will no longer activate the $/ \mathrm{skw} /$ node. 
However, even this problem is reversible during normal cognitive aging because older adults can readily replace defunct nodes with new ones: Using their intact subcortical binding mechanisms, older adults can create new cortical connections to re-represent defunct information under the James-MacKay theory. For example, a normal older adult with a defunct /skw/ node can use their intact phonological binding nodes to create a new cortical node to re-represent /skw/ on their next encounter with any of the many English words containing /skw/. Similarly, a normal older adult with defunct propositional nodes representing the meaning of the LF word squeamish can use their intact propositional binding nodes to create new cortical nodes to re-construct that meaning from a dictionary definition. A normal older adult with defunct episodic nodes representing an event experienced in the past can likewise use their intact episodic binding nodes to create new cortical nodes to re-represent this event from a second hand report.

\section{Lesion-induced Forgetting: SRA or Supranormal RA}

Under the James-MacKay theory (James and MacKay, 2001), nonrecent and infrequent use of information during the lifespan have caused structural changes in the brain at the same rate in H.M. and normal older adults. Like normal older adults, H.M. has also been able to offset the resulting transmission deficits through recent and frequent use of preoperatively familiar information. However, unlike normal older adults, H.M. and other amnesics with medial temporal lobe (MTL) damage lack the subcortical binding mechanisms essential for forming new cortical connections either to represent newly encountered information or to re-represent familiar information that has become defunct.

By way of illustration, damage to H.M.'s propositional binding nodes has rendered semantic information difficult for H.M. to learn or re-learn. This semantic "binding deficit" explains H.M.'s semantic SRA at age 44 relative to same-age memorynormal controls in Marslen-Wilson and Teuber (1975). Because H.M. cannot replace defunct propositional nodes with new ones under the James-MacKay theory, he was less able to rerepresent familiar semantic information that had become defunct than same-age memory-normal controls under the James-MacKay theory (James and MacKay, 2001).

Damage to H.M.'s episodic binding nodes has likewise rendered links between novel events and their "context-of-occurrence" difficult for H.M. to either learn or re-learn. Due to this episodic "binding deficit," H.M. would have exhibited measurable SRA for episodic information encountered a few days or more before his lesion (if his memory for these episodic events had been tested at that time, which it wasn't). The reason is that most episodic events are by definition unique or once-ina-lifetime, and without recent repetition or rehearsal and a history of frequent use or encounter over the lifespan, episodic nodes become defunct within a few days under the JamesMacKay theory. By contrast, memories for semantic information (which people might repeat on a weekly or monthly basis) become defunct more slowly, and memories for phonological information (which speakers might repeat on a daily basis) become defunct even more slowly because frequency of activation over the course of a lifetime is many orders of magnitude greater for nodes representing phonological units than for those representing unique episodic events (see MacKay, 1982). It thus seems unsurprising that H.M.'s episodic memory deficits reached the attention of the field first (Scoville and Milner, 1957), his semantic memory deficits next (Marslen-Wilson and Teuber, 1975), and his phonological memory deficits last (MacKay and James, 2002).

Under the James-MacKay theory, damage to H.M.'s phonological binding nodes has rendered novel or unfamiliar phonological forms (e.g., words and consonant clusters in an unfamiliar language) difficult for H.M. to learn since his lesion (see MacKay, Burke et al., 1998). This phonological binding deficit predicts SRA for LF and not-recently-used phonological information relative to same-age memory-normal controls at any age. However, in the years immediately after his lesion H.M. would not have exhibited measurable phonological SRA for most of the words he knew. The reason is that H.M. has repeated most pre-operatively familiar words frequently over his lifespan and recently since his lesion, thereby preserving this phonological information from becoming defunct within so short a time span under the James-MacKay theory.

\section{Aging and Lesion-Induced Forgetting: SARA}

Under the James-MacKay theory (James and MacKay, 2001; see also MacKay, 2006), age-linked transmission deficits have increased in frequency and extent at the same rate in H.M. and normal older adults since age 65 (a standard age threshold in cognitive aging research). Frequent and recent use of information has also served to offset age-linked transmission deficits to the same extent in H.M. and normal older adults. However, age-linked transmission deficits are cumulative and when deficits involving particular connections and nodes become so severe that the information they represent becomes defunct, H.M. no longer resembles normal older adults. The reason is that unlike normal older adults, H.M. and other amnesics with MTL damage lack the subcortical binding mechanisms essential for efficiently forming new cortical connections. As a result, H.M. has been unable to re-represent familiar information that has become defunct with aging since age 65 .

Because age-linked transmission deficits become worse with aging (all other factors being equal), this means that H.M.'s SRA will become SARA, progressively worsening with aging in the period between age 65 and 73 (when the present experiments were conducted). Thus, normal RA will yield relatively stable SRA in H.M. from age 26 to age 64 (by standard theoretical convention), but his SRA will become progressively worse from age 65 to 73, indicating the occurrence of SARA under the James-MacKay theory (James and MacKay, 2001). That is, measured cross-sectionally relative to same-age controls, H.M.'s normal RA because of nonrecent use and LF use of familiar information across his lifespan will diverge from 
TABLE 2.

Age, Verbal IQ, Performance IQ and Highest Educational Degree for H.M. and Control Participants in Experiments 1-3 (see text for details)

\begin{tabular}{lcccc}
\hline Participants & Age & $\begin{array}{c}\text { Verbal IQ } \\
(\text { W-B I) }\end{array}$ & $\begin{array}{c}\text { Performance } \\
\text { IQ (W-B I) }\end{array}$ & $\begin{array}{c}\text { Highest Educational } \\
\text { Degree }\end{array}$ \\
\hline H.M. & 73 & 107 & 117 & High school \\
Control 5 & 70 & 117 & 130 & High school \\
Control 12 & 71 & a & a & High school \\
Control 21 & 77 & 115 & 104 & High school \\
Control 23 & 73 & 107 & 118 & High school \\
Control 31 & 77 & 129 & 113 & High school \\
Control 39 & 72 & a & 101 & High school \\
Control 51 & 71 & 99 & 120 & High school not completed \\
Control 52 & 65 & 115 & 126 & High school \\
Control 57 & 67 & 111 & 108 & High school \\
Control 58 & 67 & 114 & 114 & High school \\
Control 59 & 70 & 116 & 115 & High school \\
Control 61 & 66 & 100 & & High school \\
\hline
\end{tabular}

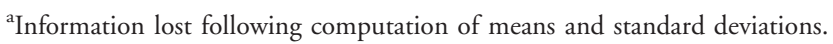

normal and become SRA at a relatively fixed rate from age 26 to 65 because unlike the controls, H.M. cannot re-instate information that becomes defunct. However, from age 65 to 73 H.M.'s SRA will become progressively worse over time when measured longitudinally relative to same-age controls, the definition of SARA.

To summarize the James-MacKay theory as applied to the connections examined in James and MacKay (2001), H.M.'s worddefinition performance indicated cross-sectional SRA that occurred when the bottom-up links between the lexical nodes for LF words and the propositions that represent their meaning became permanently defunct. H.M.'s lexical decision performance for LF words in James and MacKay likewise indicated cross-sectional SRA that occurred when the bottom-up links between the orthography and phonology of LF words and their lexical nodes became permanently defunct. Moreover, H.M.'s lexical decision performance exhibited longitudinal SARA (reliably larger deficits relative to age-matched controls at age 57 than at age 73) for LF words because progressively more bottom-up links to lexical and propositional nodes representing LF words became defunct and irreplaceable with advancing age in H.M. (relative to the controls).

\section{OVERVIEW OF THE PRESENT STUDY}

Participants in the present experiments were H.M. and 12 carefully matched memory-normal controls with background characteristics shown in Table 2: highest educational degree, age at time of test, verbal IQ, and performance IQ. The main theoretical issue at stake was whether H.M. would exhibit SRA and SARA for three types of connections in the James-MacKay theory (bottom-up, lateral, and top-down connections) and for information represented by three types of low-level nodes (lexical, phonological, and orthographic nodes). The critical con- nections in Experiment 1 were top-down links between the lexical and phonological nodes for producing the name of a pictured object. The critical connections in Experiment 2 were top-down links between the lexical node representing a word and the orthographic nodes for spelling it correctly. The critical connections in Experiment 3 were bottom-up and lateral links between the orthographic nodes and phonological nodes for reading a word aloud (see the introduction to Experiment 3 for a detailed discussion of bottom-up and lateral "ortho-phonological" connections).

Experiment 1 compared the performance of H.M. and memory-normal controls for HF and LF names on the BNT at age 73. Under the James-MacKay theory, H.M. should exhibit deficits relative to the controls in retrieving LF object names if top-down links between lexical and phonological nodes for retrieving those names are becoming permanently defunct in H.M. However, H.M. should not exhibit deficits relative to the controls in retrieving HF object names.

Experiment 1 also compared H.M.'s overall BNT performance at age 73 (Experiment 1 data), age 72 (data from Kensinger et al., 2001) and age 54 (data cited in Corkin, 1984). Under the James-MacKay theory, H.M. should exhibit retrieval deficits that become progressively larger from age 54 to 72 to age 73 relative to age-matched controls if top-down links between lexical and phonological nodes representing object names are becoming increasingly defunct with aging and causing SARA in H.M.

Experiment 2 examined H.M.'s orthographic retrieval at age 73 in a recognition memory task that focused on the irregular or difficult-to-spell aspects of familiar words, e.g., the [Y] in bicycle (This report distinguishes phonological from orthographic units using the generally accepted convention of capitalizing orthographic units within square brackets, and placing phonological units between slashes, as in this example. To fur- 
ther illustrate this distinction, the suffix in farmer is represented /-êr/ in phonology and [-ER] in orthography, and the initial letters in SQUEAMISH are represented/skw/ phonologically and [SQU] orthographically. Our phonological transcriptions of spoken speech follow the current International Phonetic Alphabet [available at: www.arts.gla.ac.uk/IPA/fullchart.html]). Under the James-MacKay theory, H.M. should exhibit deficits relative to age-matched controls at age 73 in this task if his lexical-phonological nodes and their top-down connections to orthographic nodes are becoming defunct and causing SRA. Experiment 2 also compared H.M.'s spelling performance at age 73 vs. age 72 (data from Kensinger et al., 2001). Under the James-MacKay theory, H.M. should exhibit larger deficits at age 73 than age 72 if the top-down links between lexical nodes and the orthographic nodes representing spelling are becoming defunct with aging and causing SARA.

Experiment 3 compared the performance of H.M. and memory-normal controls on a reading task involving isolated LF words. Under the James-MacKay theory, the controls should outperform H.M. on this task if orthographic nodes and their bottom-up and lateral links to phonological nodes for reading aloud are becoming permanently defunct in H.M. Experiment 3 also compared H.M.'s ability to read LF words aloud at ages 67 (data from Postle and Corkin, 1998), 71 (data from MacKay and James, 2002), and 73 (data from Experiment 3 using the Postle and Corkin stimuli). Under the James-MacKay theory, H.M. should exhibit larger reading deficits relative to age-matched controls at age 73 than at age 71 or at age 67 if orthographic nodes and their bottom-up and lateral links to phonological nodes are undergoing SARA in H.M.

\section{EXPERIMENT 1: SARA FOR PHONOLOGICAL INFORMATION}

Experiment 1 compared the performance of amnesic H.M. and age-matched memory-normal controls for HF and LF target words on the BNT, where the task is to retrieve the names of pictured objects. Although H.M. has taken the BNT many times in the past (see Corkin, 1984; and Kensinger et al., 2001), no previous study has compared performance on the BNT for H.M. vs. controls carefully matched for age, education, background, and IQ. Nor has any previous study examined H.M.'s BNT performance for HF vs. LF target words. Nor has any previous study examined effects of semantic vs. phonological cues on H.M.'s BNT performance, an essential step for determining whether H.M. exhibits SRA for phonological information. Finally, no previous study has examined whether H.M. exhibits SARA for phonological information that becomes progressively worse with aging after age 65 . To test for SARA, Experiment 1 compared H.M.'s BNT performance relative to controls at ages 73 (using the present data), 72 (using data from Kensinger et al., 2001), and 54 (using data cited in Corkin, 1984).

\section{METHOD}

\section{Participants}

The main participants were H.M. and eight memory-normal controls. The controls were selected from more than 750 older adults in the participant pools of the UCLA Cognition and Aging Laboratory and the Claremont Project on Memory and Aging. Background information for H.M. and the controls for Experiment 1 is shown in Table 2 (see Controls 5, 21, 31, 51, 52, 58, 59, and 61). The controls spoke English as children, their mean age was 70 (standard deviation $(\mathrm{SD})=3.78$ years), and they closely matched H.M. in highest education level (the high school diploma), background (unskilled or semiskilled labor), and mean IQ on the W-B I (112.5, SD = 8.06; see Kensinger et al., 2001, for reasons why the W-B 1 provides the most appropriate scores for comparing H.M. with controls). All controls reported an absence of neurological problems, and participated for $\$ 10 / \mathrm{h}$.

We tested H.M. at age 73 when his most recent IQ score on the W-B 1 was 112 (see Table 2). In 1953, H.M. underwent precision suction surgery that bilaterally removed his amygdala and part of his hippocampus and connected MTL structures, while sparing virtually his entire neocortex (see Scoville, 1968; Scoville and Milner, 1957). Since 1953, H.M. has acquired cerebellar damage, probably reflecting sustained use of dilantin for treating epilepsy. The MRI data that most recently preceded the present (1999) experiments also suggested (without data from same-age memory normal controls) "possible" and at most "minimal" damage to lateral temporal neocortex that was not because of the original 1953 surgical ablation (Corkin et al., 1997). A follow-up MRI study 10 years later compared H.M. with four memory-normal controls (unmatched with H.M. for IQ, education, or background) and excluded the possibility of Alzheimer-related degeneration but indicated vascular changes and cortical thinning of unknown etiology, unknown time of onset, and unknown relations to behavior (Salat et al., 2006). Salat et al. also noted (p. 937) that since 1997, "H.M. has had, at most, two seizures a year, with some years having no seizures at all." H.M. exhibited no signs of epileptic activity during the testing days for Experiments 1-3.

\section{Materials}

The materials came from the BNT (Kaplan et al., 1983): 60 black-and-white line drawings of animals and objects. Names for the pictures were either HF, i.e., six per million or more in Kucera and Francis (1982) ( $\mathrm{N}=15 ; M=86.2$ ) or LF, i.e., less than six per million in Francis and Kucera $(\mathrm{N}=43 ; M=$ 1.47 per million). (We matched the mean frequency of HF and LF words in the present study and MacKay and James as closely as possible. Like James and MacKay [2001] and MacKay and James [2002], we used Kucera and Francis [1982] to estimate frequency of encounter because their database was published about midway between 1953 [the year of H.M.'s lesion] and 2000 [the approximate date of test for the present 
controls]. We limited our search of the Kucera and Francis database to nouns and we excluded BNT nouns missing from the database. However, we included the singular count when the plural was missing (e.g., dominoes on the BNT), and vice versa (e.g., hanger on the BNT). The present results would not differ if all nouns missing from the database had been assigned frequency count 0 ).

\section{Procedures}

We followed the BNT procedures outlined in Kaplan et al. (1983). The pictures were presented in the standard order, beginning with easily named pictures such as bed and tree, and moving to progressively more difficult pictures such as protractor and abacus. If a participant correctly named a picture, the experimenter presented the next picture in the BNT sequence. For pictures not correctly named initially, the experimenter presented the semantic cue from the BNT, e.g., "an ocean animal" to facilitate retrieval of octopus. For pictures not correctly named either initially or with the semantic cue, the experimenter pronounced the phonological cue from the BNT, e.g., "oc" for octopus.

The experimenter presented the instructions orally and in summary form on a continuously displayed card. The experimenter also repeated the basic instructions orally to H.M. throughout the experiment, and when the semantic and phonological cues failed to yield the correct name for a picture, the experimenter gave H.M. the correct name together with a "verification question," either "Does that sound right to you?" or "Have you ever heard of that?" or "Does that word sound familiar to you?" or "You knew that before, right?" These verification questions served to ensure that H.M. once knew the correct name, thereby ruling out educational deficiency as a possible contributor to H.M.'s BNT deficits.

All sessions were tape recorded for subsequent transcription. The transcribers $(\mathrm{N}=4)$ used the label ??? when confidence in their transcription of a particular word was less than $100 \%$ and the label "inaudible" when two or more transcribers could not decipher a word after repeated replay. The transcription "inaudible" was especially common for H.M. because his articulatory quality was often poor (attributable to his cerebellar lesion), and his sentences were often vague, incoherent, and difficult-to-understand. To illustrate, when semantic and phonological cues failed to yield the target word TRELLIS, the experimenter asked H.M. whether TRELLIS sounded familiar to him, and H.M. replied: "In a way it does because they have the roses and (inaudible) that way." Three aspects of this transcribed reply are noteworthy: the incoherence of "because they have the roses" with the topic (familiarity of the word TRELLIS), the difficult-to-determine referent for H.M.'s they (Note that the target word TRELLIS is singular and requires the pronoun $i$ ), and the transcription "inaudible": As in this example, only nontarget words received the transcriptions "inaudible" and ???, an outcome indicating that H.M.'s target word results were unrelated to his difficult-to-decipher speech.

\section{RESULTS}

\section{Target Word Results}

Overall (with either no cues, with the semantic cue alone, or with the semantic and phonological cues), H.M. successfully retrieved the target word for $86.67 \%$ of the pictures, an accuracy level 2.85 SDs below the mean for the controls $(95.71 \%$, $\mathrm{SD}=3.17 \%)$. For target words not produced initially, the degree of additional help from the semantic cue did not differ reliably for the controls vs. H.M. (a 0.87 SD difference). However, for target words not produced either initially or with the semantic cue, the degree of additional help from the phonological cue was 2.38 SD greater for the controls than for H.M. Under the standard convention that differences of 2.0 SDs or more constitute deficits, present BNT data indicate that H.M. exhibited reliable deficits in retrieving the phonology for concrete words at age 73 .

H.M.'s BNT deficits were entirely attributable to LF target words. Overall, H.M. successfully retrieved $100 \%$ of the HF target words vs. a mean of $89 \%$ for the controls (SD $=7.0 \%$ ), a nonreliable 1.57 SD difference favoring HM.

Consistent with the hypothesis that H.M.'s BNT deficits reflected retrieval difficulty rather than educational deficiency, three sources of evidence indicated prior familiarity with the target words. First, H.M. often produced near-miss errors, defined as incorrect names that resembled the target word in meaning or phonology, e.g., "Like an easel" for PALLETTE (meaning similarity). Such near-miss errors are difficult to explain under the hypothesis that H.M. had never previously encountered these target words.

Second, H.M. accurately described the use or function of many stimulus objects whose names he could not retrieve, e.g., STETHESCOPE, SCROLL, PALLETTE and TRELLIS (see examples 1-4). Such functional knowledge is also difficult to explain under the hypothesis that H.M. had never previously encountered these target words.

1. H.M.: STETHESCOPE. "Well a doctor uses it to uh find out different areas of you. They uhh, yeah. Or how your heart is working and th- the noises go coming from that (inaudible) goes to other parts."

2. H.M.: SCROLL. "That they can have more rolled up and they could unroll it (Exp: Yeah) and copy it from them."

3. H.M.: PALLETTE. "Oh, it could be like for nn painting (Exp: $\mathrm{Mm} \mathrm{hmm}$ ) and you hold it and you have the little dots on it are different colors."

4. H.M.: TRELLIS. "That's to hold flowers, up, when they grow, into, uhh, in, they have places so they can grow in on in (Exp: Right) and these uhhh, oh, 'cause the bars are in the pot (inaudible) lined up, and uh the bars have to go up and they have to stay on that, uh, thing."

Third, H.M.'s responses to the experimenter's verification questions indicated familiarity with all of the target words he could not produce. For example, when semantic and phonolog- 
ical cues failed to yield the target word ASPARAGUS, H.M.'s response to the experimenter's verification question suggested that he had learned the word asparagus during childhood: "Yes... Cause uhh we had it in our soup my mother had learned how to make, the soup for the, my father, down south."

\section{Types of Errors}

\section{Neologisms}

Neologisms were scored when participants produced a nonword instead of the target name. For example, H.M. produced the nonwords "sidion" for SNAIL, "abstractor" for ABACUS, and "trake" for TRELLIS.

H.M. and the controls did not differ reliably in number of neologisms produced. However, the controls often produced a string of neologisms for the same target word, whereas H.M. never did so, a 6.0 SD difference. (By standard convention, indefinitely large deficits [as can occur when the SD for the controls is zero] are indicated as 6.0 SDs). For example, in attempting to retrieve the target word TRELLIS, a control participant produced the neologism string "tralie," "trassel," "travis," and "trussel."

H.M.'s neologisms also differed from those of the controls in their similarity to the target word: Unlike H.M.'s neologisms, the neologisms of controls always shared more than $30 \%$ of the phonological segments in the target word (e.g., "tralie-trassel-travis-trussel" for TRELLIS), a $6.0 \mathrm{SD}$ difference. For example, H.M.'s "sidion" contains fewer than $30 \%$ of the phonological segments in the target word SNAIL.

\section{Noun phrase circumlocutions}

Both H.M. and the controls produced noun-phrase circumlocutions, where a noun phrase replaced the target word. Examples involving the target word TONGS are "ice clippers" (H.M.) and "ice cube tool" (control participant). However, the controls always followed their noun-phrase circumlocutions with a noun or pseudonoun, unlike H.M., who never did so, a reliable 6.0 SD difference.

\section{Near-miss errors}

Near-miss semantic errors occurred when participants produced a nontarget word similar in meaning to the target word, e.g., "compass" for PROTRACTOR (H.M.). Near-miss phonological errors occurred when participants produced a nontarget word similar in phonology to the target word, e.g., "telescope" for STETHESCOPE (H.M.). Overall, H.M. and the controls did not differ reliably in overall number of near-miss errors.

However, the controls often produced strings of near-miss errors that ended with the target, e.g., "chipmunk," "raccoon" (near-miss errors) and then BEAVER: "it's not a chipmunk... a raccoon? No, it's not a racoon either... uhhhh... oh, he's eating... a beaver." By contrast, H.M. never produced more than one near-miss error per target, a reliable 6.0 SD difference.

\section{Superordinate errors}

Superordinate errors were scored when participants produced a superordinate name rather than the specific name for the target, e.g., "bird" for PELICAN. Superordinate errors only occurred for controls and were always corrected, as in "nut.... acorn" for ACORN and "boat ... canoe" for CANOE. H.M. produced no superordinate errors, either corrected or uncorrected, a reliable 6.0 SD difference.

\section{Noncorrection of target-word errors}

The controls usually corrected their target-word errors, as in "Dice...oh, it's uh...dominoes" (for the stimulus DOMINOES) and "ice cube tool.. (laughter) ummm, tuh, uh, tong" (for the stimulus TONG). By contrast, H.M. never corrected any of his errors on either target words (a 6.0 SD difference relative to the controls) or nontarget words (with one possible but controversial exception).

\section{Error signals}

When the controls could not correct an error, they invariably produced an "error signal" to indicate awareness of the error, e.g., "No" or "I mean" or "That's not it," or "I give up" (following a series of pseudoword responses), or laughter (as in the "ice cube tool" example noted earlier). However, H.M. never produced error signals or indicated awareness of any of his errors, a $6.0 \mathrm{SD}$ difference relative to the controls.

\section{Subsidiary Results \\ Blends and other speech errors}

The controls sometimes stuttered, e.g., "nuh-, nuh-, not a nut," and produced segment substitutions during target descriptions, e.g., "stesescope" for STETHESCOPE, whereas H.M. never did so, a reliable 6.0 SD difference. Moreover, the verification questions confirmed that none of H.M.'s nonword descriptors of BNT pictures reflected unintended phonological blends or other speech errors. For example, when asked about his "trake" neologism in Example 11, H.M. indicated that he intended to say "trake." Thus, "trake" represented neither a transcription error nor an unintended blend of the gardenrelated words trellis and rake.

\section{TRELLIS PICTURE}

H.M.: "Trake"

Exp: "Trake?" (verification query 1)

H.M.: "Yeah"

Exp: "This is actually a trellis."

H.M.: "A trellis."

Exp: "A trellis. Does that sound familiar to you?" (verification query 2).

H.M.: "In a way it does because they have the roses and (inaudible) that way."

Also noteworthy in Example 11 is the experimenter's second verification query: "Does the word TRELLIS "sound familiar 
to you?" Here H.M.'s response ("In a way it does because they have the roses...") rules out educational deficiency or unfamiliarity with trellises as the basis for the neologism "trake."

\section{Target-unrelated errors impacting grammaticality, coherence, and comprehensibility}

Unlike the controls, H.M. often produced target-unrelated errors that rendered his utterances ungrammatical, incoherent, and vague or difficult-to-understand. Examples 5-10 illustrate all four characteristics, with italics indicating uncorrected word substitutions or additions in H.M.'s utterances (see examples 1-4 for other ungrammatical, incoherent, and difficult-tounderstand utterances).

5. H.M.: SNAIL PICTURE. "An, umm, it could be a... a small in animal that goes on, in the ocean." (ungrammatical sentence)

6. H.M.: STETHOSCOPE PICTURE. "Well a doctor uses it to uh find out different areas of you. They uhh, yeah. Or how your heart is working and th the noises go coming from that (inaudible) goes to other parts." (incomplete, vague, incoherent and ungrammatical sentence)

7. H.M.: SCROLL PICTURE. "Nothing, they use to write in, bec-, so they can write on it and roll it up with one way (inaudible), so they can unroll it and read it." (incomplete, vague and ungrammatical sentence)

8. H.M.: TRELLIS PICTURE. "That's to hold flowers... up, when they grow, into, uhh, in, they have places so they can grow in on in." (vague and ungrammatical sentence)

9. H.M.: PALLETTE PICTURE. "It's just that uh thing that the painter can hold it hold different colors right there if he wants them to paint." (incomplete, vague and ungrammatical sentence)

10. H.M.: ABACUS PICTURE. "That's for counting in times. (Exp: Uh huh. Do you know a name for it?) In uhh, no, just for counting in a way, for (inaudible) so you can pass it along, these numbers (inaudible) slide up and count." (vague, ungrammatical and difficult to understand sentence).

\section{DISCUSSION}

H.M. at age 73 exhibited six reliable deficits in BNT performance relative to same-age memory-normal controls. For standard BNT measures, H.M. exhibited an overall deficit (with or without the semantic and phonological cues), and a deficit in the facilitative effect of phonological cues.

H.M. also exhibited deficits relative to the controls in refining his noun-phrase circumlocutions, in producing neologisms phonologically unrelated to a target word, in correcting his target-word errors, and in producing error signals to indicate awareness of his errors.
H.M.'s BNT deficits indicate cross-sectional SRA in H.M. at age 73 because the baseline BNT performance for our $70+$ year old controls reflects normal age-linked RA (see Barresi et al., 2000, for a recent review). In this context, H.M.'s extensive prior experience with the BNT and other picture naming tests is noteworthy: Besides taking the BNT itself a large number of times from 1953 to 2001, H.M. has received massive exposure to similar pictures in other picture naming tests. For example, H.M. took the BNT twice for a single study (Kensinger et al., 2001), together with three other (even more extensive) picture naming tests two times each. Previous picture naming studies indicate that test repetition facilitates H.M.'s performance. For example, H.M. took the Gollin incomplete pictures test four times between 1962 and 1983, with progressively fewer errors each time (see Corkin, 1984). Practice or repetition has also facilitated H.M.'s performance in a wide range of other tasks and conditions (see MacKay and James, 2002; and MacKay et al., 2008). Because the present controls lacked H.M.'s massive picture naming practice with the BNT and other picture naming tests, it therefore seems highly likely that H.M.'s BNT deficits would have been much more severe in Experiment 1 if we could have equated picture naming practice for H.M. and the controls.

To summarize, Experiment 1 demonstrated SRA for topdown phonological information in a cross-sectional comparison of H.M. and carefully matched memory-normal controls. We turn now to the question of whether H.M.'s cross-sectional SRA reflects longitudinal SARA, i.e., progressive age-linked deterioration after age 65 in H.M. that resembles his SARA for bottom-up lexical information (see James and MacKay, 2001; and MacKay and James, 2002). H.M.'s longitudinal BNT performance at ages 54, 72, and 73 suggests that it does. H.M.'s age 54 BNT data was "in the normal range" (see Corkin, 1984, p. 254) and his age 72 BNT data (from Kensinger et al., 2001) was "within 1 SD" of 19 controls matched for age and education (but not IQ). H.M.'s BNT performance therefore deteriorated from essentially normal at age 54 and 72 to a reliable deficit at age 73 relative to age-and education-matched controls. This pattern of deterioration indicates that H.M. has undergone SARA that is age-linked and progressive in nature from age 54 to age 73 .

H.M.'s deficit-free performance at age 54 and age 72 rules out educational deficiency as the basis for his age 73 BNT deficits, and is consistent with three other indications that H.M. once knew the present target words: H.M. produced near-miss errors that resembled the targets in meaning or phonology; H.M. produced accurate descriptions of how stimulus objects functioned despite inability to retrieve their name; and H.M.'s response to verification questions indicated familiarity with the target names that he could not retrieve.

What nodes and connections underlie H.M.'s SARA in Experiment 1? Phonological nodes for LF words were almost certainly the critical units and top-down links within the hierarchy of lexical-phonological nodes were almost certainly the critical connections. The reason is that providing a phonological cue facilitated recall of LF target words significantly more 
for the controls than for H.M. By contrast, three observations suggest that lexical nodes were probably not the critical units and top-down links to lexical nodes were probably not the critical connections: First, effects of a semantic cue on name retrieval did not differ reliably for H.M. vs. the controls in Experiment 1. Second, H.M. is normal in this respect because memory-normal older adults in their early 70s likewise benefit little from receiving a semantic cue on the BNT (see Barresi et al., 2000, for a recent review). Third, same-age controls in Experiment 1 produced near-miss semantic errors that resembled H.M.'s. All three observations suggest that H.M.'s semantic and lexical-level representations of the target pictures for LF words were relatively intact.

Why did phonological cues facilitate retrieval of LF words in our controls (and other memory-normal older adults; see Barresi et al., 2000) but not H.M.? By hypothesis, transmission deficits due to normal aging, nonrecent use, and infrequent use over the lifespan caused specific phonological nodes for LF words with a history of infrequent and nonrecent use to become defunct in both H.M. and the controls. However, normal older adults in their early 70s (or younger) can readily replace defunct phonological nodes with new ones when they encounter a word or a phonological cue that contains the defunct phonological information (see James and Burke, 2000). Using these recently created or reconstituted phonological units, the controls readily retrieved the full phonology for the present target words under the James-MacKay theory.

Phonological nodes and connections representing LF and not recently used words have also become defunct with aging in H.M. under the James-MacKay theory. However, due to his phonological binding deficit, H.M. has been unable to replace defunct phonological connections and nodes for LF words on subsequent encounters with phonological cues to the defunct information. More and more of H.M.'s phonological nodes therefore became and remained defunct with advancing age. As a result, H.M. exhibited deficits in retrieving BNT words relative to age-matched controls at age 73 but not at age 54 or age 72 because permanent age-linked transmission deficits emerged at age 73 that were not yet significantly different from control levels at age 72 .

However, H.M. retrieved HF words without deficits relative to age-matched controls at age 73 because H.M. has continued to use HF words throughout his life, and recent use and frequent use over the lifespan prevents nodes from becoming defunct with aging. Because no "replacement" connections were necessary for HF words under the James-MacKay theory, retrieval of HF words did not differ for H.M. vs. same-age controls.

Turning to errors in Experiment 1, H.M. produced significantly more errors than the controls for some types of error (e.g., isolated neologisms unrelated in phonology to the target word), but not others (stutters, segment substitutions, neologism strings and superordinate errors). H.M.'s error deficits were therefore selective, involving some error types but not others, just as H.M.'s overall BNT deficits were selective, with reliable deficits for LF words but not HF words. Both types of selectivity speak against general cognitive decline at age 73 and are consistent with other evidence ruling out general cognitive decline in pre-1999 tasks assessing H.M.'s visual cognition (MacKay and James, 2000), language use (MacKay et al., 2008; MacKay et al., 2007; MacKay, Burke et al., 1998; and MacKay, Stewart et al., 1998), and memory (see e.g., MacKay et al., 2008; MacKay et al., 2007).

Also noteworthy were H.M.'s deficits in correcting and indicating awareness of his BNT errors. First, H.M. has exhibited similar deficits in error detection and correction on a wide range of other tasks (see MacKay et al., 2007, 2008; and MacKay and James, 2002). Second, H.M.'s problems in creating novel internal representations make sense of his problems in detecting and correcting errors: Because error detection depends on perceiving a mismatch between the internal representation for an error vs. an intended action, error detection cannot occur when binding deficits prevent the formation of internal representations (see MacKay, 1992; MacKay et al.).

Third, H.M.'s problems with error detection and correction may explain several other aspects of the present results. One is the fact that H.M. produced reliably more phonologically dissimilar errors than the controls: Unlike H.M., the controls may have been able to filter out phonologically dissimilar errors such as "sidion" for SNAIL prior to overt speech (see MacKay, 1992). Deficits involving error detection and correction may also explain why H.M. failed to hone in on a target via successive approximations at the phonological level (as when controls but not H.M. produced strings of phonologically similar neologisms before producing a target word), at the lexical level (as when controls but not H.M. produced superordinates before producing a target word), and at the phrase level (as when controls but not H.M. replaced noun-phrase circumlocutions with nouns).

Turning to subsidiary results, H.M.'s ungrammatical, incoherent, and vague or difficult-to-understand utterances in Experiment 1 (see Examples 5-10) replicate and extend earlier observations indicating that H.M. produces similar utterances reliably more often than controls in a wide variety of tasks (see e.g., MacKay et al., 2008; MacKay et al., 2007; also MacKay, Burke et al., 1998; and MacKay, Stewart et al., 1998).

Unlike H.M.'s cortical-level SRA and SARA for phonological information, H.M.'s ungrammatical, incoherent, and difficultto-understand utterances represent a relatively constant feature of H.M.'s language production over the period 1970-1999, and according to MacKay et al. (2008), directly reflect the damage to his (subcortical) semantic binding mechanisms and resulting deficits in forming new (cortical) connections. However, whatever their cause, the errors underlying utterances such as examples 5-10 contradict the hypothesis of Skotko et al., (2005, p. 406-7) that H.M.'s spoken discourse is "without major errors." For example, even the seemingly minor nontarget error in Example 5 (H.M.'s "small in animal”) can be considered major because it rendered his sentence ungrammatical, and was uncorrected, yielding the potential to interfere with efficient communication. 
EXPERIMENT 2: SUPRANORMAL AGE-LINKED ORTHOGRAPHIC RA

In Experiment 2, amnesic H.M. and age-matched memorynormal controls retrieved LF orthographic information in a spelling recognition task. Only one other study (Kensinger et al., 2001) has examined spelling in H.M. (at age 72), and that study had several flaws. First, the control participants took the Kensinger et al. spelling test only once, whereas H.M. took the test twice (a significant flaw because in general, repetition or practice improves H.M.'s performance; see MacKay and James, 2002; and MacKay et al., 2008). Second, the Kensinger et al. control participants were unmatched with H.M. for IQ and general background. Without adequately matched control participants who receive the same treatment as H.M., conclusions regarding (non-)deficits are open to question. Third, most of the words in Kensinger et al. were HF or very HF and regularly spelled, e.g., time, go, up. Such materials are inappropriate for evaluating either normal or supranormal RA because both memory-normal older adults and H.M. exhibit preserved function for HF information such the rules for spelling regularly spelled English words (see MacKay and Abrams, 1998; MacKay and James, 2002).

The present recognition memory task therefore examined retrieval of orthographic information that is truly LF: irregularly spelled letters in difficult-to-spell words, e,g, the $[\mathrm{Y}]$ in thyme. To illustrate the LF nature of irregularly spelled letters, compare two words with the same phonology: the regularly spelled time [-IME], vs. the irregularly spelled thyme [-YME]. Note that most English words that rhyme with thyme are spelled [-IME] rather than [-YME], e.g., prime, dime, crime, grime, lime, time, and have greater word frequency than thyme. Irregular spellings such as [-YME] are therefore extremely LF relative to regular spellings such as [-IME] because frequency-of-encounter for a spelling depends on the number of words in the internal lexicon containing that phoneme-to-grapheme correspondence multiplied by the frequency-of-encounter of those words over the lifespan (see MacKay and Abrams, 1998).

Stimulus presentation was both auditory and visual in Experiment 2. For example, participants heard the word bicycle and saw the word bicycle spelled BIC_CLE, where the blank represents a single missing letter. They then chose one of two response alternatives (I or Y) that could fill in the blank and correctly spell bicycle. For the present study, this spelling recognition paradigm offered four advantages over the usual orthographic retrieval paradigm: presenting tape recorded words for participants to write down (see e.g., MacKay and Abrams, 1998). First, the present spelling recognition paradigm minimizes working memory load (an important consideration with H.M.): Unlike the hear-then-write-down paradigm, keeping an auditorily presented stimulus word in mind while generating its constituent letters in proper serial order was unnecessary in Experiment 2. Second, the spelling recognition paradigm eliminates the output interference that occurs in the hear-then-writedown procedure, especially for words containing repeated let- ters, e.g., statistics. Finally, the combined visual and auditory presentation format in the spelling recognition paradigm virtually eliminates perceptual errors, a common occurrence for older adults hearing isolated auditory words (see MacKay and Abrams, 1998).

\section{METHOD}

\section{Participants}

Participants were H.M. at age 73 and seven memory-normal controls resembling those in Experiment 1 (see Table 2 for background characteristics of H.M. and Controls 5, 12, 21, 23, 39, 51, and 61). The controls closely matched H.M. in mean age $(72.9, \mathrm{SD}=3.34$ years), mean performance and verbal IQ score (112.14), mean highest educational level (high school diploma), and native language (English). All controls reported an absence of neurological problems, participated for $\$ 10 /$ h. and were tested between 1999 and 2001.

\section{Materials}

The materials were 50 words (10 practice and 40 experimental) selected from Webster's (1949) dictionary to ensure entry into English at least three years before H.M.'s 1953 lesion. The words varied in length between 4 and 14 letters $(M=7.44$ letters, SD $=2.38)$, and mean frequency in Kucera and Francis (1982) was 139.27 per million $(S D=162.14)$. (We matched the mean frequency of HF and LF words in the present study and MacKay and James as closely as possible. Like James and MacKay [2001] and MacKay and James [2002], we used Kucera and Francis [1982] to estimate frequency of encounter because their database was published about midway between 1953 [the year of H.M.'s lesion] and 2000 [the approximate date of test for the present controls]. We limited our search of the Kucera and Francis database to nouns and we excluded BNT nouns missing from the database. However, we included the singular count when the plural was missing [e.g., dominoes on the BNT], and vice versa [e.g., hanger on the BNT]. The present results would not differ if all nouns missing from the database had been assigned frequency count 0). For stimulus words listed in Gilhooly and Logie (1980), mean age-of-acquisition ranged from 1.53 (indicating likely acquisition by age 2) to 4.94 (indicating likely acquisition by age 8 ), with an overall $M=4.68$ (SD = 1.02). In short, H.M. knew these stimulus words long before his age 26 lesion.

Each word was typed in capital letters in large (Courier 24) font at the top of a plain $3^{\prime \prime} \times 6^{\prime \prime}$ index card, and contained a "blank," e.g., APP_ARENTLY, and ENROLL_MENT. Two response alternatives for filling the blank appeared at the bottom of each card (separated by 14 letter spaces). The response alternatives consisted of two letters, or a letter and a blank (_), indicating that no letter was needed to correctly spell the word. For example, blank (_) rather than E was the correct response 
alternative for the stimulus APP_ARENTLY. The stimuli, their order of presentation, their correctly spelled length in letters, the two response alternatives, and the correct response alternative for each stimulus appear in the Appendix.

\section{Procedures}

The participants were instructed verbally as follows: This experiment deals with spelling. I will read a word to you and show you a card with the word correctly spelled except for a blank space. At the bottom of the card are two choices for filling in the blank, either two letters or a letter and a line (_). The line indicates that no letter should be added to correctly spell the word. Your task is to say which alternative gives the correct spelling, either a letter or the word "blank." Here is a practice example: FAT_ER. As you can see, the word is "father" (pronounced by the experimenter) and the stimulus on the card is spelled F, A, T, "blank," E, R. At the bottom of the card, you have two choices for how to spell this word correctly: $\mathrm{H}$ and _ ("blank"). So you would say "H" because that gives the correct spelling for the word "father." Do you have any questions?

As in Experiment 1, the experimenter asked follow-up questions whenever H.M. chose the wrong response alternative, a procedure that ensured familiarity with all of the stimulus words in Experiment 2. Three additional procedures ensured that H.M. understood the instructions and did not forget them during the experiment: Ten practice trials preceded the experiment proper; summary instructions appeared on a prominently placed card throughout the experiment; and the experimenter repeated the basic instructions for H.M. (but not the controls) several times during the experiment.

\section{RESULTS AND DISCUSSION}

H.M. correctly spelled 26 of the experimental words (65\%) vs. a mean of $32.86(82.14 \%)$ for the controls $(S D=3.18)$, a $2.15 \mathrm{SD}$ deficit. Under the standard convention that differences of 2.0 SDs or more represent reliable deficits, H.M. therefore exhibited a reliable deficit in orthographic retrieval relative to age-matched controls.

Three procedures ruled out educational deficiency as a factor in the present results. First, age-of-acquisition norms indicated that H.M. almost certainly knew our stimulus words before age nine. Second, the stimuli in Experiment 2 entered English at least three years before H.M.'s age 26 lesion. Third, H.M.'s responses to the follow-up questions indicated familiarity with all of the words that he misspelled in Experiment 2.

H.M. therefore knew the present stimulus words at one time, but at age 73 exhibited a retrieval deficit for irregularlyspelled aspects of those words relative to carefully matched memory-normal controls. In view of this deficit, H.M.'s extensive experience with crossword puzzles during the course of his lifetime is noteworthy. According to Skotko et al. (2004, p. 757), H.M. has been solving crossword puzzles since about age 15, and he "continues to work on two or more puzzles each day," including notoriously difficult ones featured in crossword puzzle books published by the New York Times and Merriam-Webster. Because solving crossword puzzles depends on spelling skill (among other factors), it seems likely that without such extensive and ongoing crossword puzzle experience, H.M. would have exhibited a much more severe orthographic retrieval deficit than we observed in the present task.

H.M.'s deficit at age 73 for irregularly spelled aspects of once familiar words represents supranormal orthographic RA because the baseline performance for our 73 year old controls defines normal RA (see e.g., MacKay and Abrams, 1998). Does H.M.'s supranormal orthographic RA exhibit the same cumulative or progressive nature as his SARA for phonological information in Experiment 1 and for lexical-semantic information in James and MacKay (2001)? The only longitudinal data for testing this hypothesis comes from Kensinger et al. (2001, Fig. 2, p. 353), where H.M. at age 72 performed within 1 SD of the controls. H.M.'s much larger deficit at age 73 than age 72 is therefore consistent with SARA for orthographic information (but see the caveats outlined in the introduction regarding the Kensinger et al. study).

Also consistent with SARA for orthographic information is H.M.'s SARA in word reading tasks. MacKay and James (2002) demonstrated that at age 71, H.M. misread familiar (pre-1953) LF words in unusual ways not seen in age-matched controls. For example, unlike the controls, H.M. often misread LF words in ways that bore little phonological resemblance to the target words, e.g., gulp misread as "quip" and adumbrate misread as "embryate" (see Table 3 for a complete list of H.M.'s reading errors on LF words in MacKay and James).

H.M. also exhibited major response time deficits in reading LF words at age 60 and at age 71 relative to age-matched controls, with a much larger deficit at age 71 than at age 60 . This accelerated or supranormal age-linked decline involves bottomup links from orthography, but strongly suggests that the topdown links to LF orthography that enable spelling retrieval will also exhibit accelerated or supranormal age-linked declines characteristic of SARA. The reason is that aging impairs both top-down and bottom-up processes, but impairs top-down processes more so than bottom-up processes in both orthographic retrieval (see MacKay et al., 1999) and phonological retrieval (see James and MacKay, 2007).

\section{EXPERIMENT 3: SARA FOR ORTHO- PHONOLOGICAL INFORMATION}

In Experiment 3 amnesic H.M. and age-matched memorynormal controls read LF words aloud at age 73 . Three aspects of H.M.'s age 73 reading performance are relevant to our understanding of RA and SARA. First, reading is a cued recall task, where, by definition, the cue (here, the orthography for a 
TABLE 3.

Types of Errors (with definitions and examples) that H.M. Produced Reliably More Frequently Than Memory-Normal Controls When Reading Pre-1953 LF Words in MacKay and James (2002)

\begin{tabular}{|c|c|c|}
\hline Error type & Definition & H.M.'s age 71 reading errors involving LF words \\
\hline Wrong-word Errors & A stimulus word misread as some other word. & $\begin{array}{l}\text { "sanctify" for satisfy; "lethal" for lentil; "corrupt" } \\
\text { for crypt; "lesson" for lentil; "quip" for gulp; } \\
\text { "wrench" for wretch }\end{array}$ \\
\hline Nonword errors & A stimulus word misread as a nonword. & $\begin{array}{l}\text { "embryate" for adumbrate; "embryism" for } \\
\text { euphemism; "k- kimbo" for akimbo; "abarus" for } \\
\text { abacus; "amygie" for abacus; "jetson" for } \\
\text { jettison; "glipis" for ellipsis; "papus" for } \\
\text { papyrus; "stamedia" for stamina; "emberate" } \\
\text { for adumbrate }\end{array}$ \\
\hline Successive approximations & $\begin{array}{l}\text { Two or more unsuccessful attempts to correctly } \\
\text { pronounce a word. }\end{array}$ & $\begin{array}{l}\text { "abicurgle .. duh .. abidackle.. abedickle" for } \\
\text { abdicate; "abicurgle ... "carl-ch-charl. . . } \\
\text { chameleon" for chameleon; "stam- ... stampa" } \\
\text { for stamina; "sangrate ... see-grated" for } \\
\text { serrated; "ak-akibo-akbo" for akimbo; } \\
\text { "stamedia. . .stam. . .In-a" for stamina }\end{array}$ \\
\hline Segmentation errors & $\begin{array}{l}\text { One or more segments occur in different syllables } \\
\text { in the stimulus and response. }\end{array}$ & "zel-yet" for zea-lot \\
\hline Phonologically unrelated errors & $\begin{array}{l}\text { A response sharing less than } 50 \% \text { of the stimulus } \\
\text { segments or vice versa. }\end{array}$ & raisin" for abacus; "guest" for crypt \\
\hline Repetition of earlier units & $\begin{array}{l}\text { Responses with one or more incorrect segments } \\
\text { carried over from an earlier trial. }\end{array}$ & "ambryite" after "papryism" after "embryism \\
\hline Order errors & $\begin{array}{l}\text { A syllable, segment or phoneme produced in } \\
\text { improper relative order in a stimulus word. }\end{array}$ & $\begin{array}{l}\text { papryism" for papyrus ([R] must precede }[\mathrm{Y}]) \text {; } \\
\text { abidackle" for abdicate ([A] must precede }[\mathrm{C}]) \text {; }\end{array}$ \\
\hline Suffix Errors & $\begin{array}{l}\text { Omission or substitution of a suffix in a stimulus } \\
\text { word. }\end{array}$ & $\begin{array}{l}\text { "international" for internal; "sherate" for serrated; } \\
\text { "ellipse" for ellipsis. }\end{array}$ \\
\hline Stress shifts & $\begin{array}{l}\text { Stress produced on the wrong syllable in a } \\
\text { stimulus word. }\end{array}$ & $\begin{array}{l}\text { "labrinth" (LAbyrinth) } \\
\text { efFACE; " for labyrinth; "EFfess" for } \\
\text { "stam. . IN-a" for STAmina; "A.kron" for } \\
\text { aKIMbo; "stam. . I-na" for STAmina }\end{array}$ \\
\hline
\end{tabular}

Italics indicate the stimulus word.

${ }^{a}$ Capitalization indicates a stressed syllable.

word) under-specifies the information to be retrieved (here, the phonology for the word). To illustrate how orthography underspecifies phonology in English, consider the familiar word pedestrian. On logical grounds, the letters in PEDESTRIAN fail to specify four important aspects of how speakers normally pronounce pedestrian: the number of syllables (four), the location

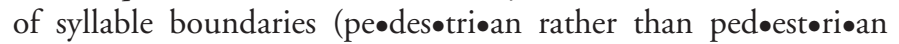
or peedeøtriøan), what syllable receives primary stress (the second, as in pe•DES •triean rather than PE pe•des•TRI•an), and the pronunciation for critical letters (e.g., speakers pronounce the first $[\mathrm{E}]$ in PEDESTRIAN as in pet rather than redo, and they pronounce the [I] in PEDESTRIAN as in peal rather than pill). In principle, then, RA for these underspecified aspects of the pronunciation of PEDESTRIAN can trigger uncorrectable reading errors. For example, RA for the phonological segments and pattern of syllabic stress in pedestrian can yield uncorrectable reading errors such as "PEA॰desøtrian" and "ped•EA•strian" ("ea" as in pea; primary stress in capitals) (see Table 3 for additional uncorrected errors resembling these).

Second, H.M.'s age 73 reading performance enables a test for RA in bottom-up and lateral connections, two types of connections not examined in Experiments 1 and 2: Experiment 1 and 2 engaged top-down links (see Fig. 1) but not the bottomup and lateral links required for word reading in Experiment 3. We use the LF word squeamish to illustrate how lateral links connect orthographic nodes to the phonological and lexical nodes for reading words aloud (Following the notational conventions outlined earlier, orthographic units are capitalized within square brackets, phonological units are placed between slashes, and stressed units are capitalized outside brackets). As MacKay and James (2002) discuss in detail, parallel node hierarchies represent orthographic and phonological information, and lateral links between these hierarchies jointly determine our 
ability to read words such as SQUEAMISH. Figure 1 illustrates the phonological hierarchy for squeamish, and orthographic units representing SQUEAMISH are organized in the same hierarchic manner: The lowest level orthographic units represent single letters, which combine or feed into higher-level orthographic units. For example, the letters $[S],[Q]$ and $[\mathrm{U}]$ in SQUEAMISH feed into a higher-level unit representing [SQU] and the letters [E] and [A] in SQUEAMISH feed into a higher-level unit representing the multi-letter vowel [EA].

These higher-level orthographic units connect laterally with the corresponding same-level units in the phonological system. For example, the [SQU] unit in the orthographic hierarchy for the word SQUEAMISH has a lateral link to the phonological unit for producing the consonant cluster $/ \mathrm{skw} /$ (as in squid), and the [EA] unit has a lateral link to the phonological unit for producing the complex vowel /iy/ (as in pea).

These same-level lateral links redundantly specify the pronunciation of English orthography. For example, the letter [S] in SQUEAMISH links laterally to the phonological segment/s/ which links bottom-up to the phonological cluster /skw/. However, the letter [S] in SQUEAMISH also links bottom-up to the orthographic cluster [SKW] which links laterally to the phonological cluster /skw/. The $[S],[Q]$, and [U] in SQUEAMISH therefore redundantly specify the phonological pronunciation /skw/: bottom-up (via the lateral [S]-to-/s/ link) and laterally (via the lateral [SQU]-to-/skw/ link).

By hypothesis, this multi-level redundancy normally offsets the under-specification of English phonology to enable errorfree reading. To illustrate, consider some of the errors that readers would make using only lower-level, letter-to-segment links without the just-discussed [EA]-to-/iy/ link for reading the word SQUEAMISH. Because the letter [A] is pronounced as in acorn or active or combat in most English words, readers would often misread SQUEAMISH as squiy-AYE-mish (with AYE stressed as in acorn), or squiy-A-mish (with A stressed as in active) or SQUIY-a-mish (with A unstressed as in combat) rather than correctly (SQUIY-mish).

In summary, error-free reading requires hierarchical bottomup and lateral orthographic connections that differ in function and structure from the top-down links for picture-naming (Experiment 1) and spelling (Experiment 2). Examining H.M.'s age 73 reading performance is therefore essential to determine whether H.M.'s bottom-up and lateral links connecting orthography with phonology are undergoing SRA, as predicted under the James-MacKay theory.

Third, H.M.'s age 73 reading performance allows a test of SARA for ortho-phonological information. Prior data for testing SARA in H.M. are absent or unavailable for many types of LF information. However, this is not the case for word reading: H.M.'s LF word reading was examined at age 71 in MacKay and James (2002) and at age 67 in Postle and Corkin (1998), and Experiment 3 used the same or similar stimuli at age 73 to test for the progressive age-linked decline predicted under the James-MacKay theory of SARA. Thus, H.M. should exhibit larger deficits relative to same-age controls when reading similar or identical LF words at age 73 (Experiment 3) than at age 71 (in MacKay and James) and at age 67 (in Postle and Corkin) if his bottom-up and lateral ortho-phonological connections are undergoing SARA.

\section{METHOD}

\section{Participants}

Participants were H.M. and six memory-normal controls resembling those in Experiment 1 (see the background characteristics of Controls 5, 23, 51, 52, 57, and 61 in Table 2). We tested H.M. in 1999 at age 73 when his mean Verbal and Performance IQ on W-B I was 112. The mean highest educational level (high school diploma) and native language (English) was the same for H.M. and the controls. We tested the controls from 1999 to 2003 when their mean age was 70 and their mean Verbal and Performance IQ on the W-B I was 113. All controls reported an absence of neurological problems and participated for $\$ 10 / \mathrm{h}$.

\section{Materials}

The materials were 100 words from Appendix A and B of Postle and Corkin (1998). Fifty were pre-1953 words that entered English dictionaries before 1953, and 50 were post1965 words that entered English after 1965. Unlike the controls, H.M. had read the same 100 words in 1993, a factor that works against observing the SARA predicted under the James-MacKay theory because H.M.'s word-specific reading performance can be expected to improve with practice or repetition (see MacKay and James, 2002; see also MacKay et al., 2008).

Postle and Corkin matched the pre- vs. post-1965 words for length in letters (range: 4-13 letters) and frequency-of-encounter in a large 1988 Associated Press database, and the pre-1953 words had mean frequency 3.89 per million $(\mathrm{SD}=3.89)$ in Kucera and Francis (1982). H.M.'s pre-lesion familiarity with the pre-1953 words was not an issue because these words were familiar to H.M. according to Postle and Corkin (1998) and the mean age of acquisition index for pre-1953 words that appeared in Gilhooly and Logie (1980) was 4.26 (SD = 1.75), indicating familiarity with those words for most children by age 7-9.

H.M.'s 1999 visual acuity was likewise not a factor in reading the present materials. First, H.M. in 1997 read without errors all 26 (randomly ordered) letters of the alphabet, presented one at a time in the same large font size, case, and font type as the present stimuli (see MacKay and James, 2002). Second, the present stimuli were words rather than isolated letters, and lexical context is known to further enhance letter discrimination. Third, because H.M. could accurately read normal font, (mostly) lower case words in 2001 (see Skotko et al., 2005), H.M. clearly had adequate acuity to accurately decipher upper case letters with larger-than-normal font in the present 1999 study. 


\section{Procedure}

Each word was typed on a separate card in large (18 point) upper case Courier font. To present each word, the experimenter turned over a card, saying "OK" as soon as the participant could see the word. Instructions were presented orally as well as visually on a continuously displayed card: "Read each item as quickly and accurately as possible."

H.M. and the controls read the 100 intermixed pre- and post-1965 words in identical random order. Responses were tape recorded for subsequent transcription. Transcription procedures resembled those in Experiment 1 except that a primary listener first transcribed the tapes word-for-word, applying the label "unintelligible" when she could not decipher one or more words on the tape and applying the label ??? when she was less than $100 \%$ sure of her transcription for a particular word. Then a second listener repeatedly listened to sections of the tape labeled "unintelligible" and ??? in the transcript, and if she preferred an alternative transcription, a third listener repeatedly listened to those sections. If the third listener favored the transcription of either listener one or two, that alternative was entered as the final transcription. However, if the third listener preferred a third alternative, "unintelligible" was entered as the final transcription. Responses labeled "unintelligible" or ??? in the final transcript were considered nonviable trials and excluded from all analyses.

\section{RESULTS}

\section{Overall Reading Performance}

When scoring overall reading performance, we counted each viable trial as correct or incorrect, independent of whether the reader subsequently corrected their error. This procedure provided a conservative estimate of H.M.'s overall reading performance relative to the controls because memory-normal controls correct their errors with reliably higher probability than H.M. in reading (see MacKay and James, 2002) and a wide range of other tasks (see MacKay et al., 2007, 2008). If we had scored only uncorrected errors, H.M.'s performance relative to the controls would have been much worse.

The controls produced a mean of 0.12 errors per viable trial $(\mathrm{SD}=0.085)$, vs. 0.67 for H.M., a reliable $6.61 \mathrm{SD}$ difference indicating an overall reading deficit. H.M. also misread a higher proportion of the stimuli than the controls: H.M. misread $66.67 \%$ of the stimuli, vs. a mean of $9.28 \%$ for the controls $(\mathrm{SD}=5.53 \%)$, a reliable $10.38 \mathrm{SD}$ difference.

\section{Effects of Word Type}

When reading pre-1953 words, the controls produced a mean of 0.127 errors per viable trial $(S D=0.118)$ vs. 0.500 errors for H.M., a reliable 3.16 SD deficit. When reading post1965 words, the controls produced a mean of 0.103 errors per viable trial $(S D=0.060)$, vs. 0.870 errors for H.M., a reliable 12.78 SD deficit. H.M. therefore performed almost $10 \mathrm{SDs}$ worse relative to the controls when he read post-1965 words than when he read pre-1953 words.

\section{Types of Reading Errors}

A separate paper (MacKay and Hadley, in preparation) will examine H.M.'s errors in this and other experiments from the perspective of reading theories. The present analyses had a more limited, age-related goal: to compare the frequency of errors that H.M. produced when reading comparable stimuli at age 73 vs. at age 71 . Specifically, the present error type analyses compared H.M.'s error frequencies by error type on pre-1953 LF words in Experiment 3 vs. in MacKay and James (2002). LF words in these studies were comparable in frequency and were familiar to H.M. before both experiments (see MacKay and James, 2002).

As in MacKay and James (2002), the present error type analyses included all responses within a trial when participants misread the same stimulus several times. Experiment 3 also adopted the same error categories as MacKay and James (2002). Table 3 shows the nine types of errors that H.M. produced reliably more frequently than memory-normal controls when reading pre-1953 LF words in MacKay and James (2002): wrong-word errors, nonword errors, successive approximations, segmentation errors, phonologically unrelated errors, repetition of earlier units, order errors, suffix errors, and stress shifts (see Table 3 for definitions and examples of these error types). Table 4 shows the comparable data from Experiment 3: H.M.'s full set of reading errors for pre-1953 LF words at age 73, categorized into the same nine error types (plus three additional error types discussed shortly).

Relative to age-matched memory-normal controls, H.M. exhibited reliable deficits for the nine error types common to Tables 3 and 4 at age 73 (Experiment 3: smallest deficit, 5.84 SDs, largest deficit, 18.43 SDs) and at age 71 (see MacKay and James, 2002). However, H.M.'s median deficit (determined instead of the mean because some of H.M.'s deficits were excessively large at age 73) for these error types was $10.95 \mathrm{SDs}$ at age 73 vs. $6.0 \mathrm{SDs}$ at age 71. In short, H.M.'s deficits for these error types were 4.95 SDs larger at age 73 than at age 71 , a reliable difference.

Moreover, H.M. exhibited reliable deficits for three additional error types at age 73 (in Experiment 3) that he did not exhibit at age 71 (in MacKay and James, 2002). These additional error types with reliable deficits at age 73 but not 71 included fluency errors (stutters and noticeable within-word pauses, e.g., thimble misread as "tim-...tim•BO•lee" (where "BO" rhymes with "toe"), segment omission errors, e.g., affirmation misread as "formation," and segment substitution errors, e.g., vase misread as "base" (see Table 4).

\section{DISCUSSION}

H.M. exhibited reading deficits in Experiment 3 that varied in magnitude as a function of word type and aging. With regard to word type, H.M. exhibited an approximately $3.0 \mathrm{SD}$ 
TABLE 4 .

Types of Errors that H.M. Produced Reliably More Frequently Than Memory-Normal Controls When Reading Pre-1953 LF Words in Experiment 3

Error type

Wrong-word Errors

Nonword errors

Successive approximations

Segmentation errors

Phonologically unrelated errors

Repetition of Earlier Units

Order errors

Suffix errors

Stress shifts

Fluency errors

Segment omission errors

Segment substitution errors

H.M.'s age 73 reading errors involving pre-1953 LF words

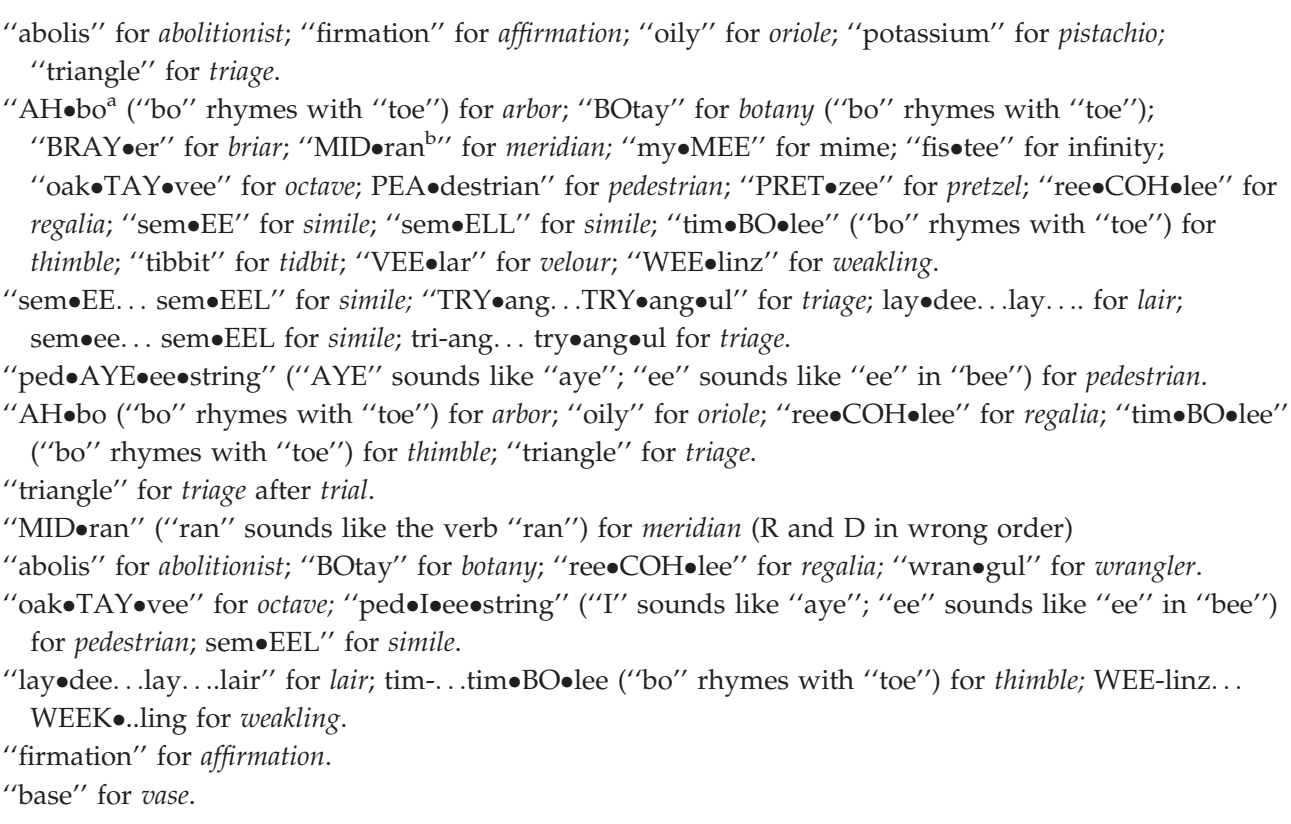

Italics indicate the stimulus word (see Table 3 for corresponding error type definitions).

${ }^{a}$ Capitalization indicates a stressed syllable.

b، •” indicates segmentation or syllable boundaries.

deficit for pre-1953 words vs. an almost 13.0 SD deficit for post-1965 words. This 10 SD difference indicates that word type modulated H.M.'s reading deficits and is readily explained in terms of familiarity: H.M. was familiar with all of the pre1953 words prior to his lesion, but the post-1965 words were unfamiliar to H.M. because his 1953 lesion prevented the formation of an internal representation for these words (see also Postle and Corkin, 1998).

With regard to aging, H.M. misread about $49 \%$ of the present stimuli in 1993 (Postle and Corkin, 1998, p. 426) vs. 67\% in 1999 (Experiment 3). (We could not determine H.M.'s 1993 deficits in SDs because Postle and Corkin did not report error data for same-age controls, and we were unable to obtain the Postle and Corkin data so as to calculate H.M.'s 1993 deficits in SDs relative to new same-age controls). This $18 \%$ increase in errors over the 6 year period between age 73 (1999) and age 67 (1993) is consistent with SARA, i.e., supranormal age-linked decline in the retrieval of ortho-phonological information. Moreover, this $18 \%$ increase in errors almost certainly underestimates the true difference: Because H.M. read the same stimuli in 1993 and 1999 and because practice with identical stimuli reliably improves H.M.'s reading performance (see MacKay and James, 2002), H.M. would almost certainly have performed even worse in 1999 if he had not received the 1993 practice. (In addition, this $18 \%$ difference almost certainly underestimates the true difference in other ways. For example, in calculating their $49 \%$ error rate, Postle and Corkin [1998] included 28 unspecified practice stimuli, which almost certainly inflated H.M.'s true 1993 error rate relative to the Experiment 3 data for experimental stimuli alone).

Also consistent with SARA, H.M.'s deficits were 4.95 SDs larger at age 73 (in Experiment 3) than at age 71 (in MacKay and James, 2002), even though the pre-1953 stimuli had somewhat higher mean age of acquisition in MacKay and James (9.7) vs. Experiment 3 (8.0) and somewhat lower mean frequency in MacKay and James (0.92 per million) vs. Experiment 3 (3.89 per million). Likewise consistent with SARA, H.M. produced reliably more fluency errors, syllable omission errors and segment substitution errors than controls at age 73 (in Experiment 3) but not at age 71 (in MacKay \& James).

Present evidence indicating accelerating declines in H.M.'s reading performance from 1993 to 1999 extends other evidence from the period 1986 to 1997 . When reading LF words in 1986 (at age 60), H.M. exhibited a 51\% deficit relative to agematched controls, and H.M.'s deficit increased to $211 \%$ by 1997 (at age 71 ; see MacKay and James, 2002). This $160 \%$ drop in reading performance indicates SARA or supranormal age-linked decline over the 11-year period between 1986 and 1997. 


\section{GENERAL DISCUSSION}

In summary, present results indicated SRA in H.M. for three types of information: phonological information for naming pictures of familiar objects (Experiment 1), orthographic information for spelling familiar LF words (Experiment 2), and orthophonological information for reading familiar LF words aloud (Experiment 3). Present results also indicated SARA in H.M. for the same three types of information: phonological information (Experiment 1), orthographic information (Experiment 2), and ortho-phonological information (Experiment 3). That is, relative to age-matched controls, H.M. exhibited progressively larger deficits as a function of age for phonological information (Experiment 1) and orthographic information (Experiment 2). Two sources of data in Experiment 3 also indicated accelerated age-linked decline for ortho-phonological information: an $18 \%$ increase in errors from age 67 to age 73 in reading identical words, and the emergence between age 71 and age 73 of reliable deficits involving three new error categories: syllable omissions, segment substitutions, and fluency errors. The present experiments therefore extend the James and MacKay (2001) demonstration of SARA for lexical-semantic information to three new types of information: phonological, orthographic, and orthophonological information.

Under the James-MacKay theory of RA, H.M.'s SRA for phonological information in Experiment 1 implies a phonological binding deficit (observable as a difficulty in learning new phonological forms; see MacKay, Stewart et al., 1998); H.M.'s SRA for orthographic information in Experiment 2 implies an orthographic binding deficit (observable as a difficulty in learning new spelling patterns in a language unlike English); and H.M.'s SRA for ortho-phonological information in Experiment 3 implies an ortho-phonological binding deficit (observable as a difficulty in learning to read new ortho-phonological patterns in a language unlike English).

Turning to the evidence for SARA in the present experiments, this evidence indicates age-linked degradation in three types of connections (top-down, bottom-up, and lateral connections) and three types of nodes (lexical, phonological, and orthographic nodes) under the James-MacKay theory of SARA. In short, present results comport with the connection-universal premise in the James-MacKay theory of SARA: that age-linked transmission deficits are independent of connection type (topdown, bottom-up, or lateral). Present results also comport with the node-universal premise in the James-MacKay theory: that SARA due to age-linked transmission deficits involves all types of cortical nodes (including lexical, phonological, and orthographic nodes).

Of course, Experiments 1-3 did not examine all types of cortical nodes and further research will be necessary to test whether effects of aging on SRA are truly node-universal. However, available evidence on aging and world knowledge or semantic information adds plausibility to the node-universal premise. For the first 18 years after H.M.'s lesion, researchers believed that H.M. exhibited only one memory problem: extremely severe anterograde amnesia (AA) involving deficits in representing, retrieving, and/or consolidating episodic and semantic information encountered initially after his 1953 trauma. However, relative to age-matched controls H.M. began to exhibit mild RA at age 44 for semantic information about people who achieved fame before his lesion (see MarslenWilson and Teuber, 1975) and his semantic RA became more severe by age 57 (see Corkin, 1984). This pattern suggests a progressive decline: No RA for many years after H.M.'s lesion, mild RA beginning around 18 years postlesion, and severe RA 31 years postlesion and subsequently, precisely the progressive age-linked pattern predicted under the James-MacKay theory. In short, available data suggest that H.M. exhibits SARA for semantic information as well as for phonological, orthographic, and lexical-semantic information, consistent with the node-universal premise of the James-MacKay theory. This adds plausibility to the node-universal premise because mean frequency and recency of retrieval differs greatly for world knowledge vs. lexical, phonological and orthographic information.

\section{SARA and Other Characteristics of SRA}

Any theory of SRA or greater-than-normal RA must explain SARA, i.e., progressive effects of aging on SRA. Conversely, any theory that explains SARA must also explain other, already established characteristics of SRA. The James-MacKay theory explains (and predicted) SARA but represents a relative newcomer among SRA theories. This section examines whether the James-MacKay theory can explain the other phenomena addressed in the wide range of SRA theories that have been proposed since Ribot (1882), e.g., Cohen and Squire, 1981; Moscovitch and Nadel, 1998; Nadel and Moscovitch, 1997; Squire and Alvarez, 1995; Wickelgren, 1979 (see e.g., Brown, 2002, for a recent review). What are some of these other phenomena? One is a weak link between AA and SRA for semantic and episodic information that is frequently but not always observed in amnesics. Although all amnesics exhibit AA by definition, observed correlations between AA and SRA have been weak and variable across studies: low correlations between the severity of AA and SRA have been reported, and not all amnesics have exhibited cross-sectional SRA relative to same-age memory-normal controls (see e.g., Kapur, 1993, for a review).

Another phenomenon requiring explanation in SRA theories concerns the differing nature of AA vs. SRA (see e.g., Hodges, 1995, Kapur, 1993, and Kopelman et al., 1999, for reviews). Unlike AA in amnesics such as H.M., SRA is often "patchy" (e.g., with "islands" of intact memory for salient or frequently used pre-lesion episodes), variable in severity across different types of memory, temporally-graded (with greater sparing of remote than recent events, e.g., Albert et al., 1979), and variable as a function of time-since-trauma (e.g., Hunkin et al., 1995; Kapur, 1993; Levin et al., 1985; Murre, 1996). The present data and other evidence from H.M. indicate another difference between SRA and AA. Whereas H.M.'s SRA has become progressively worse with aging relative to age-matched controls, H.M.'s AA for new information has remained 
relatively constant since his lesion (see MacKay and James, 2001, 2002). (Because normal cognitive aging also causes AA as well as RA relative to younger adults [see MacKay and Burke, 1990], the qualifier "relative to age-matched controls" in this statement is important to note).

Some SRA theories explain the weak correlations between AA and SRA and the differing characteristics of AA vs. SRA more readily than other theories. We focus here on a relatively recent account that Nadel and Moscovitch (1997, p. 225) characterize as "more biologically and psychologically plausible" than "standard" SRA theories. Under this "retrieval cue hypothesis" (see e.g., Bright et al., 2006; Moscovitch and Nadel, 1998; Nadel and Moscovitch, 1997), the hippocampus creates one or more new retrieval cues following each instance of memory retrieval and these additional retrieval cues facilitate subsequent retrieval of the original memory. For example, telling a friend over coffee about the time you met H.M. will link the original (distant) memory of meeting H.M. to the conversation and the coffee shop, and these newly created links provide additional cues that indirectly facilitate subsequent retrieval of the original memory of meeting H.M. Damage to the hippocampus therefore prevents the formation of these new retrieval cues and renders episodic memories less retrievable in amnesics.

This retrieval cue hypothesis (and the more general, encoding variability framework; see e.g., Glenberg, 1977) readily explains why SRA but not AA for episodic memories is often temporallygraded over several postlesion decades: Because people retrieve distant episodic memories more often than recent ones during their lifetimes (other factors being equal), distant memories will enjoy more retrieval cues, and exhibit less RA and SRA than recent memories under the retrieval cue hypothesis.

However, the present data on SRA and SARA for orthographic, phonological and orthophonological information are difficult to explain under this retrieval cue account. For example, retrieval of phonological segments during everyday handwriting, typing, reading, internal speech, and overt speech occurs billions of times during the course of a lifetime. Phonological units should therefore enjoy so many retrieval cues in older adults as to be immune to RA under the retrieval cue hypothesis (contrary to the present data).

As another problem for the retrieval cue hypothesis, it is difficult to imagine what newly created retrieval cues might facilitate future retrieval of orthographic, phonological and orthophonological units. For example, consider the distant memory for the spelling of BICYCLE (acquired during grade school). If (by conservative estimate) H.M. retrieved the correct spelling for BICYCLE on a thousand different occasions in the 15 years between age 10 and age 25, what specific cues for retrieving the spelling of BICYCLE did he acquire during those thousand retrieval trials, and how could those specific cues plausibly facilitate future retrieval of BICYCLE beyond the cues already provided in Experiment 2: the response alternatives (I or Y) and their orthographic context (BIC_CLE)?

The low correlations between RA and AA are also difficult to explain under the retrieval cue hypothesis. If the formation of retrieval cues varies with the extent of $\mathrm{AA}$, and reduced re- trieval cues explain SRA, then the severity of SRA and AA should be highly correlated under the retrieval cue hypothesis.

The James-MacKay theory of SRA explains the same phenomena as the retrieval cue hypothesis while avoiding its problems. Like the retrieval cue hypothesis, the James-MacKay theory explains SRA as an indirect rather than direct consequence of AA: Onset of AA hinders the re-representation of defunct memories in the James-MacKay theory but does not cause normal RA, does not cause memories to become defunct, and does not directly cause SRA in amnesics.

However, unlike the retrieval cue hypothesis, the JamesMacKay theory readily explains cross-sectional SRA for any type of information (semantic, episodic, orthographic, phonological, and ortho-phonological). Also unlike the retrieval cue hypothesis, the James-MacKay theory readily explains the low correlations between SRA and AA. Three factors render normal RA supranormal and permanent under the James-MacKay theory: Nonrecent use of the information since the onset of AA, extreme disuse of the information over the lifetime, and advanced age. Samples of amnesics with variable age, variable times since the onset of their AA, and variable lifetime use of the information being tested in different studies can therefore be expected to yield low correlations between SRA and AA under the James-MacKay theory. Moreover, younger amnesics (say, under age 30) who are tested on frequently used information soon after onset of AA can be expected to exhibit no SRA whatsoever under the James-MacKay theory. Variability in ageat-test, in time-since-trauma-when-tested and in age at the time of trauma therefore readily explains the variable extent of SRA in the different amnesic samples tested with different stimuli in different laboratories under the James-MacKay theory.

The James-MacKay theory also readily explains the differing characteristics of AA and SRA. Unlike the stability of AA in amnesics such as H.M., SRA tends to be variable or patchy, e.g., with "islands" of intact memory for salient information. Under the James-MacKay theory, the SRA-free islands reflect HF usage and the patchiness reflects variability in how frequently an amnesic has used or rehearsed different pre-morbid memories. However, the damage to binding nodes that causes AA remains constant under the James-MacKay theory.

As another difference, SRA, unlike AA, often (but not always; see e.g., Brown, 2002) exhibits a temporal gradient, with less SRA relative to memory-normal controls for remote than recent pre-trauma memories (see e.g., Bright et al., 2006; Kapur and Brooks, 1999). Like the retrieval cue hypothesis, the James-MacKay theory readily explains this inverse recency gradient. To illustrate this explanation, assume that memory $\mathrm{R}$ in amnesic $\mathrm{X}$ represents an event occurring shortly before the amnesia-causing trauma, and that memory $\mathrm{D}$ represents a distant event occurring long before the amnesia-causing trauma. For the purposes of this illustration, assume also that memories $\mathrm{R}$ and $\mathrm{D}$ exist in a same-age memory-normal control and have undergone the same history of use in the control as in the amnesic up to the time of the trauma. Finally, assume that memories $\mathrm{R}$ and $\mathrm{D}$ are either defunct or nondefunct in the amnesic but are nondefunct in the same-age memory-normal 
control at the time of test (usually 1.3 to 5 years after the lesion; see Scoville and Milner, 1957). This third assumption makes sense because our hypothetical example is intended to illustrate variation in the strength of SRA in amnesics relative to a control baseline, and amnesics cannot exhibit memory variability relative to normal controls under any of the three remaining possibilities: that memories $R$ and $D$ are defunct in both the amnesic and the memory-normal control (yielding equivalent RA in the amnesic and the control), or that memories $\mathrm{R}$ and $\mathrm{D}$ are nondefunct in the amnesic and defunct in the control, yielding RA in the control but not in the amnesic, a never-previously-observed phenomenon that can be called subnormal RA (Although irrelevant to the present illustration, subnormal RA represents a distinct possibility under the JamesMacKay theory: The reason is that amnesics may retrieve or use their pre-lesion memories more frequently than memorynormal controls retrieve or use corresponding memories formed during that same time period. H.M. certainly seems to retrieve pre-lesion memories with exceptionally high frequency during conversational speech [see Marslen-Wilson, 1970. Biographical interviews with H.M. Unpublished transcript, pp. 1-144], perhaps because, unlike memory-normal controls, H.M. has virtually no post-lesion memories to retrieve).

Now consider the fate of memory $R$ under these assumptions. Recently formed memories such as $\mathrm{R}$ have connections that are weak and unstable relative to memories with a long history of use because newly-formed connections lose their connection strength rapidly over time (see MacKay and Burke, 1990). Thus, during the months or years that typically intervene between trauma and test, the connections representing memory $\mathrm{R}$ are likely to lose their weak connection strength and become permanently defunct in amnesic X (because binding deficits prevent the re-representation of defunct memories). However, memory $\mathrm{R}$ in the memory-normal control is by assumption intact or nondefunct after this same interval because controls can re-represent memory $\mathrm{R}$ after it becomes defunct over time. Generalizing this example, amnesics will exhibit SRA with little sparing of memories for recent (pretrauma) events relative to memory-normal controls.

By contrast, memory D, which was formed many years before the amnesia-causing trauma, will have similar connection strength in the amnesic and memory-normal control. In the memory-normal control, memory D has remained nondefunct by assumption because the control has used (and perhaps re-represented and reused) memory D many times during the years between distant event D' and the time-of-trauma for the amnesic. Because of this long history of use, memory $\mathrm{D}$ will therefore be strong and stable in both the control and the amnesic (because the amnesic can also re-represent defunct information up to the time-of-lesion and because by assumption, memory $\mathrm{D}$ undergoes the same history of use in the control and amnesic up to that time). Thus, unlike memory $\mathrm{R}$, memory $\mathrm{D}$ will be nondefunct with about the same probability in the amnesic and the control. In short, amnesics will in general exhibit sparing of memories for distant events and will exhibit greater SRA for recent than remote memories relative to memory-normal controls.
However, the James-MacKay theory predicts two systematic exceptions to the inverse recency gradient that may help explain instances where SRA is nonexistent or remains constant across D vs. R memories, a pattern that Brown (2002) calls "flat RA." One theoretical exception concerns the interval between the amnesia-causing event and the time of test. The JamesMacKay theory predicts a delayed onset of SRA, with no SRA for $\mathrm{R}$ memories tested shortly after the amnesic event because nodes only become defunct after weeks, months or years of nonuse. Although delayed onset of SRA has been demonstrated in animals (e.g., Hughes et al., 1970; Palfai and Kurtz, 1973), "in humans.... there has been no scientific study of this" (Wickelgren, 1979, p. 52). The second theoretical exception to the inverse recency gradient concerns older amnesics (experiencing normal age-linked RA) who attempt to retrieve LF memories (which become defunct more readily than HF memories) many years after the amnesia-causing trauma (so that aging, LF and nonrecent use during that period renders both memory $\mathrm{R}$ and memory $\mathrm{D}$ permanently defunct). For these conditions, the James-MacKay theory predicts that amnesic X will exhibit "flat RA" (equally severe SRA for LF memory R and LF memory D). Future tests of these predictions are important because no other theories of RA predict these exceptions to the inverse recency rule. For example, people retrieve distant memories more often than recent memories (other factors such as retrieval rate being equal), so that distant memories will enjoy more retrieval cues and suffer less RA than recent memories without these systematic exceptions under the retrieval cue hypothesis.

\section{Acknowledgments}

We thank Dr. Lori James for testing H.M. in 1999 and Dr. Suzanne Corkin for permission to test H.M. We thank Dr. Meredith Shafto for data analyses and Alicia Chang, Kethera Bates, Meghan Gould, Hera Kan, Diane Marian, Airalee Tan, and Dr. Jenifer Taylor for general research assistance. Dr. D. Burke generously provided control participants from the Claremont Project on Memory and Aging. Pamela Crombie and Irwin Stein recruited control participants from the UCLA Cognition and Aging Laboratory and the Claremont Project on Memory and Aging.

\section{REFERENCES}

Albert MS, Butters N, Levin J. 1979. Temporal gradients in the retrograde amnesia of patients with alcoholic Korsakoff's disease. Arch Neurol 36:211-216.

Barresi BA, Nicholas M, Connor LT, Obler LK, Albert ML. 2000. Semantic degradation and lexical access in age-related naming failures. Aging Neuropsychol Cogn 7:169-178.

Bright P, Buckman J, Fradera A, Yoshimasu H, Colchester ACF, Kopelman MD. 2006. Retrograde amnesia in patients with hippocampal, medial temporal, temporal lobe, or frontal pathology. Learn Mem 13:545-557.

Brown AS. 2002. Consolidation theory and retrograde amnesia in humans. Psychon Bull Rev 9:403-425. 
Burke DM. 2006. Representation and aging. In: Bialystok E, Craik FIM, editors. Lifespan Cognition: Mechanisms of Change. New York: Oxford University Press. pp 193-206.

Burke DM, Kester-Locantore J, Austin AA, Chae B. 2004. Cherry pit primes Brad Pitt: Homophone priming effects on young and older adult's production of proper nouns. Psychol Sci 15:164-170.

Burke DM, MacKay DG, Worthley JS, Wade E. 1991. On the tip of the tongue: What causes word finding failures in young and older adults? J Mem Lang 30:542-579.

Burke DM, Shafto MA. 2008. Language and aging. In: Craik FIM, Salthouse TA, editors. The Handbook of Aging and Cognition. Hillsdale, NJ: Lawrence Erlbaum Associates. pp 373-444.

Cohen NJ, Squire LR. 1981. Retrograde amnesia and remote memory impairment. Neuropsychologia 19:337-356.

Corkin S, Amaral DG, González RG, Johnson KA, Hyman BT. 1997. H.M.'s medial temporal lobe lesion: Findings from MRI. J Neurosci 17:3964-3979.

Corkin S. 1984. Lasting consequences of bilateral medial temporal lobectomy: Clinical course and experimental findings in H.M. Semin Neurol 4:249-259.

Gilhooly KJ, Logie RH. 1980. Age-of-acquisition, imagery, concreteness, familiarity, and ambiguity measures for 1,944 words. Behav Res Methods Instrum 12:395-427.

Glenberg AM. 1977. Influences of retrieval processes on the spacing effect in free recall. J Exp Psychol [Hum Learn] 3:282-294.

Hodges JR. 1995. Retrograde amnesia. In: Baddeley AD, Wilson BA, Watts FN, editors. Handbook of Memory Disorders. New York: Wiley. pp 81-108.

Hughes RA, Barrett RJ, Ray OS. 1970. Retrograde amnesia in rats increases as a function of ECS-test interval and ECS intensity. Physiol Behav 5:27-30.

Hunkin NM, Parkin AJ, Bradley VA, Burrows EH, Aldrich FK, Jansari A, Burdon-Cooper C. 1995. Focal retrograde amnesia following closed head injury: A case study and theoretical account. Neuropsychologia 33:509-523.

James LE, MacKay DG. 2001. H.M., word knowledge and aging: Support for a new theory of long-term retrograde amnesia. Psychol Sci 12:485-492.

James LE, Burke DM. 2000. Phonological priming effects on word retrieval and tip-of-the-tongue experiences in young and older adults. J Exp Psychol [Learn Mem Cogn] 26:1378-1391.

James LE, MacKay DG. 2007. New age-linked asymmetries: Aging and the processing of familiar versus novel language on the input versus output side. Psychol Aging 22:94-103.

Kaplan E, Goodglass H, Weintraub S. 1983. Boston Naming Test. Philadelphia: Lea \& Febiger.

Kapur N. 1993. Focal retrograde amnesia in neurological disease: A critical review. Cortex 29:217-234.

Kapur N, Brooks D. 1999. Temporally-specific retrograde amnesia in two cases of discrete bilateral hippocampal pathology. Hippocampus 8:247-254.

Kensinger EA, Ullman MT, Corkin S. 2001. Bilateral medial temporal lobe damage does not affect lexical or grammatical processing: Evidence from amnesic patient H.M. Hippocampus 11:347360.

Kopelman MD, Stanhope N, Kingsley D. 1999. Retrograde amnesia in patients with diencephalic, temporal lobe or frontal lesions. Neuropsychologia 27:939-958.

Kucera H, Francis WN. 1982. Frequency Analysis of English Usage: Lexicon and Grammar. Boston: Houghton Mifflin.

Levin HS, High WM, Meyers CA, von Laufen A, Hayden ME, Eisenberg HM. 1985. Impairment of remote memory after closed head injury. J Neurol Neurosurg Psychiatry 48:556-563.

MacKay DG. 2006. Aging, memory and language in amnesic H.M. Hippocampus 16:491-495.

MacKay DG. 1992. Awareness and error detection: New theories and paradigms. Conscious Cogn 1:199-225.
MacKay DG. 1982. The problem of flexibility, fluency and speedaccuracy trade-off in skilled behavior. Psychol Rev 89:483-506.

MacKay DG, Abrams L. 1998. Age-linked declines in retrieving orthographic knowledge: Empirical, practical, and theoretical implications. Psychology and Aging 13:647-662.

MacKay DG, Abrams L, Pedroza MJ. 1999. Aging on the input versus output side: Age-linked asymmetries between detecting versus retrieving orthographic information. Psychol Aging 14:3-17.

MacKay DG, Burke DM. 1990. Cognition and aging: A theory of new learning and the use of old connections. In: Hess T, editor. Aging and Cognition: Knowledge Organization and Utilization. Amsterdam: North-Holland. pp 281-300.

MacKay DG, Burke DM, Stewart R. 1998. H.M.'s language production deficits: Implications for relations between memory, semantic binding, and the hippocampal system. J Mem Lang 38:28-69.

MacKay DG, James LE. 2000. Binding processes for visual cognition: A "hippocampal amnesic" (H.M.) exhibits selective deficits in detecting hidden figures and errors in visual scenes. Poster presented to the Cognitive Neuroscience Society, San Francisco, California.

MacKay DG, James LE. 2001. The binding problem for syntax, semantics, and prosody: H.M.'s selective sentence-reading deficits under the theoretical-syndrome approach. Lang Cogn Process 16: 419-460.

MacKay DG, James LE. 2002. Aging, retrograde amnesia, and the binding problem for phonology and orthography: A longitudinal study of "hippocampal amnesic" H.M. Aging Neuropsychol Cogn 9:298-333.

MacKay DG, James LE, Taylor JK, Marian DE. 2007. Amnesic H.M. exhibits parallel deficits and sparing in language and memory: Systems versus binding theory accounts. Lang Cogn Process 22:377452.

MacKay DG, James LE, Hadley C. 2008. Amnesic H.M., language production, and memory: Selective deficits on the test of language competence. J Exp Clin Neuropsychol 30:280-300.

MacKay DG, Stewart R, Burke DM. 1998. H.M. revisited: Relations between language comprehension, memory, and the hippocampal system. J Cogn Neurosci 10:377-394.

Marslen-Wilson W, Teuber H-L. 1975. Memory for remote events in anterograde amnesia: Recognition of public figures from news photographs. Neuropsychologia 13:353-364.

Moscovitch M, Nadel L. 1998. Consolidation and the hippocampal complex revisited: In defense of the multiple-trace model. Curr Opin Neurobiol 8:297-300.

Murre JMJ. 1996. TraceLink: A model of amnesia and consolidation memory. Hippocampus 6:675-684.

Nadel L, Moscovitch M. 1997. Memory consolidation, retrograde amnesia, and the hippocampal complex. Curr Opin Neurobiol 7:2172227.

Palfai T, Kurtz P. 1973. Time-dependent effects of Metrazol on memory. Pharmacol Biochem Behav 1:55-59.

Postle BR, Corkin S. 1998. Impaired word-stem completion priming but intact perceptual identification priming with novel words: Evidence from the amnesic patient H.M. Neuropsychologia 36:421440.

Rastle KG, Burke DM. 1996. Priming the tip of the tongue: Effects of prior processing on word retrieval in young and older adults. J Mem Lang 35:586-605.

Ribot T. 1882. Diseases of Memory. London: Kegan Paul, Trench \& Co.

Salat DH, van der Kouwe AJW, Tuch DS, Quinn BT, Fischl B, Dale AM, Corkin S. 2006. Neuroimaging H.M.: A 10-year follow-up examination. Hippocampus 16:936-945.

Scoville WB. 1968. Amnesia after bilateral mesial temporal-lobe excision: Introduction to case H.M. Neuropsychologia 6:211-213.

Scoville WB, Milner B. 1957. Loss of recent memory after bilateral hippocampal lesions. J Neurol Neurosurg Psychiatry 20:11-21. 
Skotko B, Kensinger EA, Locascio JJ, Einstein JG, Rubin DC, Tupler LA, Krendl AC, Corkin S. 2004. Puzzling thoughts for H.M.: Can new semantic memories be anchored to old semantic memories? Neuropsychology 18:756-769.

Skotko BG, Andrews E, Einstein G. 2005. Language and the medial temporal lobe: Evidence from H.M.'s spontaneous discourse. J Mem Lang 53:397-415.

Squire LR, Alvarez P. 1995. Retrograde amnesia and memory consolidation: A neurobiological perspective. Curr Opin Neurobiol 5:169-177.
Van Gorp WG, Satz P, Kiersch ME, Henry R. 1986. Normative data on the Boston Naming Test for a group of normal older adults. J Clin Exp Neuropsychol 8:702-705.

Webster's new collegiate dictionary. 1949. Springfield, MA: G \& C Merriam.

Wickelgren WA. 1979. Chunking and consolidation: A theoretical synthesis of semantic networks, configuring, S-R versus cognitive learning, normal forgetting, the amnesic syndrome, and the hippocampal arousal system. Psychol Rev 86:44-60.

\section{APPENDIX}

TABLE A1.

The Experimental Stimuli in Experiment 2, Their Order of Presentation, Their Response Alternatives, the Correct Response Alternative, Their Correctly Spelled Form, and Their Length in Letters

\begin{tabular}{|c|c|c|c|c|c|}
\hline Stimuli & Response alternatives & Correct response & Correctly spelled form & Order of presentation & Length in letters \\
\hline S_LD & $(\mathrm{U}, \mathrm{O})$ & $\mathrm{O}$ & sold & 1 & 4 \\
\hline IN_OCUOUS & $\left(\_, N\right)$ & $\mathrm{N}$ & innocuous & 2 & 9 \\
\hline DO_TOR & $\left(\mathrm{C}, \_\right)$ & $\mathrm{C}$ & doctor & 4 & 6 \\
\hline RHYTH_M & $(, \mathrm{U})$ & _- & rhythm & 5 & 6 \\
\hline LIB_ARY & $\left(\mathrm{R}, \_\right)$ & $\mathrm{R}$ & library & 6 & 7 \\
\hline PROPELL_R & $(\mathrm{E}, \mathrm{O})$ & $\mathrm{E}$ & propeller & 9 & 9 \\
\hline OCCUR_ENCE & $\left(\mathrm{R}, \_\right)$ & $\mathrm{R}$ & occurrence & 10 & 10 \\
\hline MA_OR & $(\mathrm{J}, \mathrm{G})$ & $\mathrm{J}$ & major & 11 & 5 \\
\hline FANTA_Y & $(\mathrm{S}, \mathrm{C})$ & S & fantasy & 12 & 7 \\
\hline CO_PLE & $(, U)$ & $\mathrm{U}$ & couple & 13 & 6 \\
\hline _ENERAL & $(\mathrm{G}, \mathrm{J})$ & $\bar{G}$ & general & 18 & 7 \\
\hline INTELL_GENCE & $(\mathrm{E}, \mathrm{I})$ & I & intelligence & 19 & 12 \\
\hline VID_O & $(\mathrm{E}, \mathrm{I})$ & $\mathrm{E}$ & video & 20 & 5 \\
\hline DEVELOP_MENT & $\left(\mathrm{E}_{-}\right)$ & _- & development & 21 & 11 \\
\hline DETA_CH & $(, \mathrm{T})$ & - & detach & 22 & 6 \\
\hline A_QUAINT & $(\mathrm{C},-)$ & C & acquaint & 23 & 8 \\
\hline CAMO_FLAGE & $(, \mathrm{U})$ & $\mathrm{U}$ & camouflage & 24 & 10 \\
\hline SERVI_E & $(\mathrm{S}, \mathrm{C})$ & $\mathrm{C}$ & service & 25 & 7 \\
\hline SEC_ION & $(\mathrm{T}, \mathrm{S})$ & $\mathrm{T}$ & section & 26 & 7 \\
\hline PRE_IDENT & $(S, C)$ & $\mathrm{S}$ & president & 27 & 9 \\
\hline EA_Y & $(\mathrm{S}, \mathrm{Z})$ & S & easy & 28 & 4 \\
\hline ENROL_MENT & $(\mathrm{L}, \ldots)$ & $\mathrm{L}$ & enrollment & 29 & 10 \\
\hline QUES_ION & $(\mathrm{S}, \mathrm{T})$ & $\mathrm{T}$ & question & 37 & 8 \\
\hline CONGRA_ULATIONS & $(\mathrm{T}, \mathrm{D})$ & $\mathrm{T}$ & congratulations & 38 & 15 \\
\hline RECOM_END & $(, M)$ & M & recommend & 39 & 9 \\
\hline PERSIST_NCE & $(\mathrm{A}, \mathrm{E})$ & $\mathrm{E}$ & persistence & 40 & 10 \\
\hline
\end{tabular}

